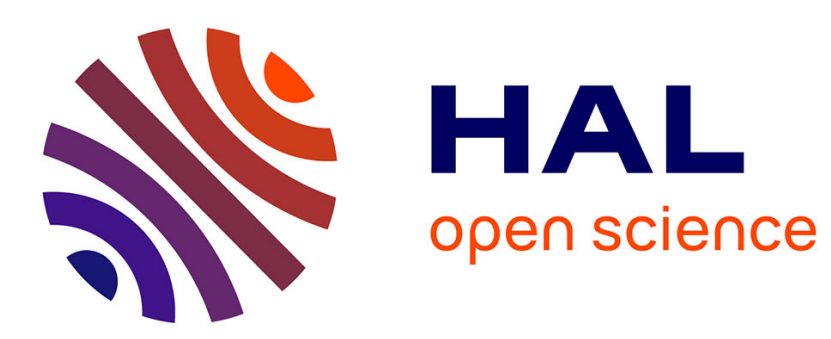

\title{
Optimal recycling under heterogeneous waste sources and the environmental Kuznets curve
}

Fouad El Ouardighi, Konstantin Kogan, Raouf Boucekkine

\section{To cite this version:}

Fouad El Ouardighi, Konstantin Kogan, Raouf Boucekkine. Optimal recycling under heterogeneous waste sources and the environmental Kuznets curve. 2017. hal-01693488

\section{HAL Id: hal-01693488 \\ https://essec.hal.science/hal-01693488}

Preprint submitted on 26 Jan 2018

HAL is a multi-disciplinary open access archive for the deposit and dissemination of scientific research documents, whether they are published or not. The documents may come from teaching and research institutions in France or abroad, or from public or private research centers.
L'archive ouverte pluridisciplinaire HAL, est destinée au dépôt et à la diffusion de documents scientifiques de niveau recherche, publiés ou non, émanant des établissements d'enseignement et de recherche français ou étrangers, des laboratoires publics ou privés. 


\section{E \\ ESSEC \\ BUSINESS SCHOOL}

\section{OPTIMAL RECYCLING UNDER \\ HETEROGENEOUS WASTE SOURCES \\ AND THE ENVIRONMENTAL KUZNETS CURVE}

RESEARCH CENTER

FOUAD EL OUARDIGHI, KONSTANTIN KOGAN, RAOUF BOUCEKKINE

ESSEC WORKING PAPER 1711

NOVEMBER 2017 


\title{
OPTIMAL RECYCLING UNDER HETEROGENOUS WASTE SOURCES AND THE ENVIRONMENTAL KUZNETS CURVE
}

\author{
FOUAD EL OUARDIGHI \\ ESSEC Business School, 95021 Cergy Pontoise, France (Corr. author: elouardighi@essec.fr) \\ KONSTANTIN KOGAN \\ Bar-Ilan University, Ramat-Gan, 52900, Israel, E-mail: kogank@biu.ac.il \\ RAOUF BOUCEKKINE \\ Aix-Marseille University, Marseille, 13002, France, E-mail: Raouf.Boucekkine@univ-amu.fr
}

\begin{abstract}
We investigate how the relationship between economic growth and pollution is affected by the source of pollution: production or consumption. We are interested in polluting waste that cannot be naturally absorbed, but for which recycling efforts aim to avoid massive pollution accumulation with harmful consequences in the long run. We distinguish the cases where recycling efforts are capital-improving or capital-neutral. Based on both environmental and social welfare perspectives, we determine how the interaction between growth and polluting waste accumulation is affected by the source of pollution, i.e., either consumption or production, and by the fact that recycling may or may not act as an income generator, i.e., either capital-improving or capital-neutral recycling efforts. Several new results are extracted regarding optimal recycling policy and the Environmental Kuznets Curve. Beside the latter concern, we show both analytically and numerically that the optimal control of waste through recycling allows to reaching larger (resp., lower) consumption and capital stock levels under consumption-based waste compared to production-based waste while the latter permits to reach lower stocks of waste through lower recycling efforts.
\end{abstract}

Keywords: Economic growth, Capital, Consumption, Polluting waste, recycling efforts.

JEL Classification. Q57, C61.

\section{Introduction}

The Environmental Kuznets Curve (EKC hereafter) conjectures that pollution is an inverse Ushaped function of economic development indicators such as income or capital stock (Grossman and Krueger, 1995): nations undergo a phase of expansion of both capital (or income) and pollution followed by decreasing pollution and further expansion of capital (e.g., Dinda, 2004). Beyond a certain turning point, capital growth should lead to a cleaner environment. The intuition behind this conjecture has been explained in Stokey's (1998) seminal work on a variety of optimal growth models: under mild regularity conditions on preferences for consumption versus environmental quality, it might be optimal for an economy above a certain threshold level of income to trade off a lower level of consumption for better environmental quality. Thus, the economies below a certain income level cannot afford the costs of pollution reduction.

The EKC has been explored in numerous empirical (Tucker, 1995; List and Gallet, 1999; Roca, 2003, among many others) and theoretical studies (see, for example, John and Pecchenino, 1994, Andreoni and Levinson, 2001, Dinda, 2005, Stokey, 1998, Prieur, 2007, and Boucekkine et al., 2013), along with the surveys of Stern (2004) and Kijima et al. (2010). Theoretically, the EKC is one possible shape of the relationship between income and pollution (Stokey, 1998). Indeed, it has been already shown that the EKC is not robust to the theoretical framework chosen. For 
example, Prieur (2007) demonstrated that introducing irreversible pollution rules out the EKC in diverse cases. Boucekkine et al. (2013) reach the same conclusion. They extend the setting of irreversible pollution to allow optimal ecological and technological regime switching under pollution irreversibility: they found that an inverse U-shaped curve arises only when a technological switch alone is optimal and the initial capital and pollution stocks are both sufficiently high.

The empirical literature is even more inconclusive (see Stern, 2004). A key finding is that the relationship between pollution and income greatly depends on the type of pollutant. Indeed, while sulfur dioxide and nitrous oxide emissions show an inverse $U$ relationship with respect to income, $\mathrm{CO}_{2}$ (see de Bruyn and Opschoor, 1997, and Sengupta, 1997) seems to exhibit an N shape, meaning that pollution starts increasing again after a decrease to a particular level. More recently, Sephton and Mann (2016) provide strong support for the environmental Kuznets curve in Great Britain, with estimated turning points in 1966 and 1967 for $\mathrm{CO}_{2}$ and $\mathrm{SO}_{2}$, respectively. Bernard et al. (2015) confirm an inverted U-shaped EKC in the OECD countries for carbon dioxide and sulfur. In contrast, no univocal robust evidence of the EKC emerges for methane and nitrous oxide emissions in the Italian regional agriculture (Coderoni and Esposti, 2014). Finally, according to Bassetti et al. (2013), whenever it is observed, the environmental Kuznets curve seems to be only a transitory phenomenon for carbon emissions. Given the persistently mixed empirical results, the methodological debate on the relevance of using standard reduced-form models (see Kijima et al., 2010, for details) is still current.

This paper makes a theoretical contribution to the EKC literature. An important yet unexamined question is how the interaction between capital growth and pollution accumulation is affected by the source of pollution. Broadly speaking, polluting waste can emanate either from a unique source, that is manufacturing activities only (e.g., mineral wastes such as cement, or glass wastes) or consumption activities only (e.g., cellulose acetate-based materials as cigarette butts, soda cans, polythene), or from hybrid sources, i.e., both manufacturing and consumption activities (e.g., plastics). The case of plastics has become a global pollution since the formation of wide garbage patches in the Pacific (Eriksen et al., 2013) and Atlantic (Law et al., 2010) oceans.

Depending on whether the polluting waste emanates from a stock of productive capital (e.g., Stokey, 1998; Dinda, 2005; Boucekkine et al., 2013) or from consumption flows (e.g., Lusky, 1976; Andreoni and Levinson, 2001), the long-run effects on the stocks of capital and polluting 
waste, and therefore their policy implications, might differ significantly. In this paper, we investigate how the tradeoff between capital growth and pollution accumulation is affected by the source of pollution - productive capital or consumption—, and identify which source of pollution should be mitigated first to enhance environmental and welfare performance.

We are interested in polluting waste either for which natural absorption takes extremely long, i.e., several centuries, (e.g., iron, aluminium, mineral residues) or which is non-biodegradable (e.g., plastic, computer hardware). Consequently, in both cases, no natural abatement that prevents solid waste accumulation can be reasonably assumed. In this setup, recycling efforts are required to avoid massive accumulation with harmful long-run consequences. We include recycling efforts in our analysis of the optimal tradeoff between economic growth and polluting waste. However, regardless of the source of pollution, recycling efforts generate secondary waste that creates negative externalities and hence social disutility. We distinguish two cases: the one where recycling efforts benefit capital accumulation, i.e., capital-improving (CI) recycling efforts, and the case where no additional revenue is drawn from recycling efforts, i.e., capital-neutral (CN) recycling efforts. Capital-neutral recycling reflects a depreciation of the qualitative properties of recycled volume (e.g., Martin, 1982), while CIR is an effective recycling process. An illustration of CIR can be found in the European plastics industry, where 60 million tons of plastics diverted from landfills are equivalent to over 66 billion euros (Plastics Europe, 2015).

The present paper adds to the literature because it disentangles the respective influences of the pollution sources on capital accumulation, on the one hand, and construes recycling as a possible income generator, on the other hand. More precisely, we will tackle three distinct sets of original questions:

- How do consumption and production-based polluting waste respectively affect the short and long-term performances of the economy as measured by consumption, capital stock, recycling effort or the stock of waste? What is the role played by income generation through recycling in the latter outcomes?

- How do consumption and production-based polluting waste respectively affect the interaction between capital and polluting waste accumulation from both environmental and social welfare perspectives? Which source of pollution should be reduced to favor the emergence of an EKC path? 
- How do CIR efforts influence the interaction between capital growth and polluting waste accumulation from both environmental and social welfare perspectives? Does CIR contribute to the existence of an EKC path?

To address these questions, we start with the preliminary analysis conducted by Boucekkine and El Ouardighi (2016) where net social utility is gained from consumption and lost by negative externalities due to polluting waste and recycling efforts. The latter frame is enriched to examine the two general sets of questions listed just above. In particular, we extend the work of Boucekkine and El Ouardighi (2016) by, among others, precisely assessing the respective influences of the pollution sources and the effectiveness of recycling on economic growth. To compare meaningfully the consequences of the optimal control of consumption versus production-based waste via recycling, we start with the analytical benchmark case where one additional unit of consumption yields the same additional waste as a supplementary unit of production. In this framework, we prove that under consumption-based waste the central planner reaches larger consumption and capital stock levels than under production-based waste. The main rational behind such an important property is that when waste is generated through production, there is an explicit brake on capital accumulation induced by the environmental negative externality, which limits both capital accumulation and therefore consumption. It turns out that this mechanism (brake on capital accumulation) is inactive under consumption-based waste. Several other comparison properties can be extracted analytically on the stock of waste and resulting optimal recycling efforts: in particular, we can show that the optimal control of waste allows to reaching lower stocks of waste through lower recycling efforts in the production-based waste case. Numerical experiments are conducted outside the benchmark case defined above to check the robustness of the analytical results and to identify the cases where the EKC emerges as well.

\section{Relation to the literature}

The setting explored here differs from the existing models on the EKC and recycling in three essential ways. First of all, it differs from the pioneering one-sector AK framework first proposed by Stokey (1998) and considerably enriched since then (see, e.g., Boucekkine et al., 2013, for a recent refinement incorporating irreversible pollution) in that consumption is treated as an alternative source of pollution that cannot be naturally abated. More importantly, we model recycling explicitly and account for the fact that recycling may generate additional income, which 
is not the case of the typical abatement activities implicitly or explicitly considered in the settings à la Stockey (see Andreoni and Levinson, 2001, for a deep discussion of the implications of the specification of the abatement technology for the EKC).

Second, our theory also clearly departs from the typical specifications in the existing papers explicitly devoted to the role of recycling under pollution accumulation. As a matter of example, our set-up differs from the well-known specifications due to Lusky (1976) along two directions. On one hand, there is no capital accumulation in the latter paper and pollution exclusively derives from consumption. Next, Lusky differentiates between the original consumption good and the recycled consumption good to model the extra income (or welfare) arising from recycling. We don't make such a differentiation and keep the one-sector AK setting à la Stokey. Instead, as explained above, we assume that recycling directly generates extra income, which may enhance capital accumulation (referred to as the CIR case here above).

Third, being a Stokey-like one-sector optimal growth model, we do not consider a separate recycling sector (as we do not a consider a distinct recycled good as explained above), and therefore we do not incorporate into the analysis the interaction and market structure implications of such a sector competing with the one producing the original good. This is done, for example, in Martin (1982), or in a more recent contribution by Fodha and Magris (2015).

As mentioned above, our paper builds on Boucekkine and El Ouardighi (2016). Clearly enough, the latter is a preliminary investigation of the dynamic properties of the same class of models. The analysis conducted in this work is however different in two essential aspects. First of all, and more importantly, Boucekkine and El Ouardighi (2016) only deliver a quick analysis of the potential outcomes of this type of models. For example, the implications for the EKC are given in two short paragraphs (page 123) as a comment on rough simulations. No characterization is provided for optimal recycling policy. As explained above, here we seek for example to examine which type of recycling (CIR or CNR, production or consumption-based) is more effective in terms of social welfare. We believe that this type of questions has such particular policy relevance that they deserve to be comprehensively addressed.

Second, there is also an analytical specification difference. Rather to stick to the typical instantaneous utility function used in growth theory, that's the logarithmic utility function, we go linear-quadratic. Both functions are of course particular. However, the linear-quadratic utility functions can be seen as (local) accurate approximations of any concave utility functions, which 
explain their popularity in economics (see Kydland and Prescott, 1982, and in particular Christiano, 1990, on the excellent accuracy of linear-quadratic utility approximations) and in operation research. The main reason of this choice is, of course, the possibility to go much further in the analytical characterization of the steady states and corresponding comparative statics, and the optimal dynamics as well. Indeed, with a linear production function (AK), linear pollution functions and quadratic preferences, we have the simplest structure to go as far as possible in such an analytical characterization. Last but not least, it's fair to recognize that linear-quadratic preferences have some unpleasant features (like the occurrence of optimal corner solutions) or specific implications, we do comment briefly on that along the way and disregard the economically irrelevant outcomes.

The paper is structured as follows. Section 2 develops the central planner model where polluting waste is a by-product of either consumption or production. In Section 3, we derive the qualitative properties of the model under both consumption and production-based waste. Section 4 compares and contrasts the results, and section 5 concludes the paper.

\section{Model}

Following standard assumptions (e.g., Stokey, 1998; Boucekkine et al., 2013), we consider an economy that continuously exploits productive capital, denoted by $K(t) \geq 0$, where $t$ stands for time, to linearly generate a flow of revenue, $a K(t)$, where $a>0$ is the constant marginal revenue generated by the productive capital stock. The revenue generated allows a certain consumption level, denoted by $c(t) \geq 0$.

Polluting waste, denoted by $w(t) \geq 0$, is caused by either the production or the consumption process (Boucekkine and El Ouardighi, 2016). In the case where polluting waste emanates from the exploitation of productive capital (production-based waste), we assume that $w(t)=\alpha a K(t)$, where $\alpha>0$ is the marginal wasting impact of production. In the case where polluting waste emanates from consumption (consumption-based waste), we assume that $w(t)=\beta c(t)$, where $\beta>0$ is the marginal wasting impact of consumption.

To reduce the stock of polluting waste, denoted by $W(t) \geq 0$, the economy may, in all cases, invest in recycling efforts $v(t) \geq 0$ over time. We assume that the waste-generating processes and recycling operations are mutually independent so that the recycling efforts are non-proportional 
to the waste emissions. This assumption allows for unbounded recycling efforts, i.e., $v(t) \leq w(t)$, to account for the possibility of reduction of past waste emissions. Due to the generally long time span of natural absorption of the waste, we assume that there is no natural abatement of pollution waste. In economic terms, this implies that the social planner cannot benefit from any natural amenities.

Finally, a fixed proportion of recycled waste is supposed to possibly generate additional revenues, $\varphi v(t)$, and therefore to positively influence capital growth, $\varphi \geq 0$ being the marginal revenue from recycling. If $\varphi=0$, however, recycling has a neutral impact on capital growth due to an ineffective recycling process. For simplicity, we also assume zero capital depreciation.

Based on the previous assumptions, the endogenous capital growth process is given as:

$$
\dot{K}=a K(t)-c(t)+\varphi v(t), \quad K(0)=K_{0} \geq 0
$$

where a positive difference between the total revenues from capital and recycled waste, and current consumption results in investment in productive capital, while a negative difference leads to disinvestment. The initial endowment in productive capital is given by $K_{0} \geq 0$.

The specification above is original and thus deserves some comments and justifications. In first place, it is important to understand that the specification just above, that is, the modeling of income generation through recycling, is exclusively aimed to capture the link between recycling and growth. It turns out that the unique engine of growth in this model is capital accumulation because the production function is AK. This explains why income generation goes to capital accumulation, and not to consumption for example in our model. Whether recycling may be capital reducing is not an issue here for two reasons. First, as explained in the introduction, we are referring to primary recycling activities where part of the waste in channeled into a recycling sector (not explicitly modeled in our social optimum framework). This sector may generate big or small profits (see the introduction); we assume that these profits go at least partially to investment in order to capture the link between growth and recycling, and we model the size of this growth effect linearly through the term $\varphi v(t), \varphi$ measuring the marginal growth effect of recycling. It could be the case, of course, that part of the waste (in particular production waste) come from capital goods in the workplace. For example, some of these goods may be scrapped for environmental reasons: typically, the oldest capital goods are the most polluting (see the vintage capital literature, for example Boucekkine et al. (2011) for a survey, and Azomahou et al. (2012), 
for an explicit modelling of the latter environmental nexus). In such a case, the loss in value due the scrapping has to be considered in addition to recycling profits in the law of motion of capital. We do assume here that the net effect is positive. Note that this is the most acceptable assumption as the scrapped goods are the oldest, the dirtiest and also the least productive goods. Last but not least, the model works even though we relax the positivity of parameter $\varphi$, we only stick to the most acceptable case.

The general law of motion of polluting waste is given by:

$$
\dot{W}=\alpha a K(t)+\beta c(t)-v(t), \quad W(0)=W_{0} \geq 0
$$

where $\alpha>0$ reflects production-based waste and $\beta>0$ consumption-based waste. In both cases, the recycling efforts are such that $\dot{W} \underset{<}{\geq} 0, \forall t>0$, for a given initial waste stock, $W_{0} \geq 0$.

We now define the objective function. In this regard, we assume that the social utility is the difference between the utility drawn from current consumption and the costs incurred from the waste stock and the recycling efforts, respectively. The instantaneous utility from current consumption is a linear quadratic function, that is, $c(t)(\theta-c(t) / 2)$, where $\theta>0$ is the utilitymaximizing consumption level (see the justification of this choice, notably with respect to Boucekkine and El Ouardighi, 2016, in the introduction).

Further, the waste stock entails negative externalities such as environmental destruction and biomass extinction (Barnes, 2002), and related health consequences. These negative externalities are internalized by the central planner and valued as an increasing convex function of the waste stock, that is, $e W(t)^{2} / 2$, where $e>0$ is a disutility coefficient associated with the waste stock. Lastly, regardless of whether they are related to consumption or production-based waste, recycling efforts generally involve separation and transformation processes that generate secondary polluting waste in the form of polluting emissions, incineration residues (e.g., clinker), etc., which also creates negative externalities. The disutility engendered by these negative-effects is expressed as an increasing quadratic function denoted by $f v(t)^{2} / 2$, with $f>0$. Without loss of generality, $f$ is normalized to one, which implies that $e$, the disutility coefficient of waste, could be interpreted relative to 1 , as the disutility coefficient of recycling.

If $r>0$ denotes the discounting rate, we assume that the social planner is sufficiently patient that the net marginal revenue generated by the productive capital stock is strictly positive (i.e., 
$a-r>0$ ) to allow sustained capital accumulation (Stokey, 1998).

Assuming an infinite planning horizon, the social planner's optimal control problem is:

$$
U=\int_{0}^{\infty} e^{-r t}\left[c(t)\left(\theta-\frac{c(t)}{2}\right)-\frac{e W(t)^{2}}{2}-\frac{v(t)^{2}}{2}\right] \mathrm{d} t
$$

subject to:

$$
\begin{array}{ll}
\dot{K}=a K(t)-c(t)+\varphi v(t), & K(0)=K_{0} \geq 0 \\
\dot{W}=\alpha a K(t)+\beta c(t)-v(t), & W(0)=W_{0} \geq 0
\end{array}
$$

under the control constraints $c(t) \geq 0$ and $v(t) \geq 0$, and the state constraints $K(t) \geq 0$ and $W(t) \geq 0$.

\section{Analytical properties of the optimal paths}

We successively determine the optimal consumption and recycling policies related to consumption and production-based waste generation, and characterize the nature of convergence to the corresponding steady state, if any. For each source of waste generation, we assess the longrun effects of recycling effort on capital growth.

\subsection{Consumption-based waste generation}

In this case, we assume that $\alpha=0$ and $\beta>0$ in the law of motion of polluting waste (3).

\section{Optimality}

Skipping the time index for convenience, the current-value Hamiltonian is:

$$
H=c\left(\theta-\frac{c}{2}\right)-\frac{e W^{2}}{2}-\frac{v^{2}}{2}+\lambda(a K-c+\varphi v)+\mu(\beta c-v)
$$

where $\lambda \equiv \lambda(t)$ and $\mu \equiv \mu(t)$ are costate variables, $j=1,2$, that evolve according to:

$$
\begin{aligned}
& \dot{\lambda}=(r-a) \lambda \\
& \dot{\mu}=r \mu+e W
\end{aligned}
$$

under the transversality conditions: $\lim _{t \mapsto \infty} e^{-r t} \lambda(t)=0$ and $\lim _{t \mapsto \infty} e^{-r t} \mu(t)=0$.

Hereafter, we shall work on the interior solutions of the problem (if any). Clearly, we could have extended the analysis to corner solutions. In particular, the optimal solutions with zero recycling may be interesting. However, corner solutions do emerge naturally in linear-quadratic problems as the Inada conditions are not fulfilled. For the linear-quadratic approximation to make sense 
both mathematically and economically, one has to concentrate on non-trivial steady states. That's why we disregard corner solutions hereafter. Assuming interior solutions, necessary conditions for optimality are:

$$
\begin{aligned}
& H_{c}=\theta-c-\lambda+\mu \beta=0 \Rightarrow c=\theta-\lambda+\beta \mu \\
& H_{V}=-v+\lambda \varphi-\mu=0 \Rightarrow v=\varphi \lambda-\mu
\end{aligned}
$$

From (5), we get $\lambda(t)=G e^{(r-a) t}$, where $G$ is a constant of integration. Given that $a-r>0$, this solution satisfies the transversality condition regardless of whether $G$ is different from zero or not. In all cases, $\lambda$ is zero at the steady state. This implies that, in the long run, the capital stock is disregarded and that the controls depend only on the implicit value of the waste stock.

Because the stock of polluting waste has a negative marginal influence on the social planner's objective function, we should have $\mu<0$. Similarly, because the capital stock positively affects the consumption rate, we should have $\lambda \geq 0$. Therefore, the greater the implicit value of the capital stock and the implicit cost of the waste stock, the lower the consumption rate in (7). The reason is clear: a high implicit value of the capital stock acts as an incentive to increase the capital stock, which can be achieved by a decrease in the consumption rate and, in the case of a CIR effort, an increase in the recycling effort. Conversely, the greater the implicit price of the capital stock and the implicit cost of the waste stock, the greater the recycling effort in (8). An implicitly costly waste stock is thus an incentive to decrease the waste stock, which can be done by lowering the consumption rate and increasing the recycling effort.

Lemma 1. The necessary conditions are sufficient for optimality.

Proof. See Appendix A1.

Indeed, the sufficient conditions used are true only for interior solutions (see Seierstadt and Sydsaeter, 1987, p. 187). In connection with the comments above on the costate variables, it is also possible to characterize the link between non-binding optimal trajectories (which are the unique economically relevant here) and the signs of the corresponding costates.

Lemma 2. Let the state constraint $W \geq 0$ be non-binding. Then, it always holds that $\mu<0$. Further, let the state constraint $K \geq 0$ be non-binding, then $\lambda>0$ if $\lambda(0)>0$ and $\lambda<0$ when $\lambda(0)<0$. In addition, we have: $\lim _{t \mapsto \infty} \lambda=0$.

Proof. See Appendix A2. 


\section{Steady state}

Plugging the value of $c$ and $v$ from (7) and (8) in (2) and (3) for interior solutions, respectively, the equations:

$$
\begin{aligned}
& \dot{K}=a K-(\theta-\lambda+\mu \beta)+\varphi(\lambda \varphi-\mu) \\
& \dot{W}=\beta(\theta-\lambda+\mu \beta)-\lambda \varphi+\mu
\end{aligned}
$$

along with (5) and (6), form the canonical system in the state-costate space. We can then prove existence and uniqueness of the steady state under a precise parametric constraint.

Proposition 1. In the case where $\beta \varphi<1$, the steady state is unique and nontrivial, given by:

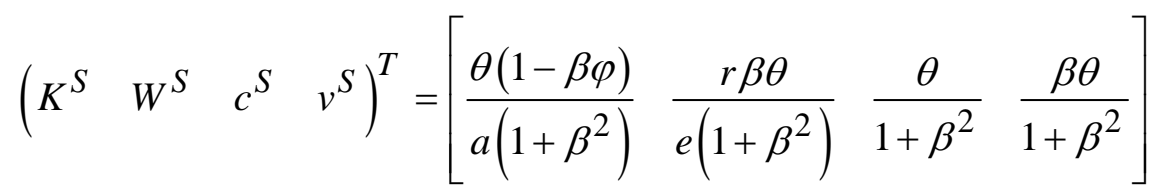

where the superscript ' $S$ ' stands for steady state.

Proof. See Appendix A3.

The steady state in (11) exists in spite of the condition for sustained long-term growth $a>r$ (Rebelo, 1991). This is due to two ingredients of the model. First, the central planner accounts for the existence of a negative environmental externality. This is a classical result, first identified by Stokey (1999). Second, preferences are linear-quadratic: even without the environmental externality, that's only keeping the consumption term in instantaneous utility, the economy would not grow indefinitely. The parametric condition $\beta \varphi<1$ is worth commenting. Notice if this condition fails to hold, stationary capital becomes negative. This comes from the accumulation equation (2) and (3) in the steady state which jointly imply:

$$
a K^{S}=c^{S}-\varphi v^{S}=c^{S}(1-\beta \varphi)
$$

It can be shown that if $\beta \varphi<1$ is violated, the unique equilibrium compatible with the nonnegativity constraints is the trivial equilibrium where all variables are nil. As explained before, we disregard this type of equilibrium, which is an artefact of the linear-quadratic preferences. Moreover the larger $\varphi$ or $\beta$, the lower the capital stock. This looks at first glance odd at least in what concerns the impact of parameter $\varphi$. Indeed, if this parameter increases ceteris paribus, recycling generates income and both $v$ and $K$ should trivially go up in first reaction. However, as income and production are raised, consumption will also increase by a mere income effect, 
which tends to curb capital accumulation. The overall effect on capital either in the short or long run is therefore ambiguous. This ambiguity shows up clearly in the long run $\left(a K^{S}=c^{S}-\varphi v^{S}\right)$. In our analytical case, the overall effect is negative and capital goes down when $\varphi$ increases. The same kind of reasoning can be applied to interpret the impact of a rising $\varphi$ on stationary waste, recycling or consumption. Concerning the stock of waste, by its law of motion, a larger would in principle, as above, increase the recycling effort, therefore driving it down. But again as above, the resulting second-round income effect would push consumption up, resulting in more waste. It appears the two effects offset each other in the current analytical configuration.

One can draw some more comparative statics from the expressions of the steady state variables' values given here above. Interestingly enough, an increase in $\beta$ unambiguously decreases longterm consumption but its effect on both recycling and total waste depends on the position of $\beta$ with respect to 1 . In the normal case where $\beta<1$ (that's one marginal unit of consumption generates less than one unit of waste), a further increase in $\beta$ raises the long-term recycling effort but also the stock of waste. With our specifications, while stationary consumption decreases when $\beta$ rises, the flow of waste $\beta c^{S}$ does increase in the long-run.

As to the parameters of the utility function, one can note that a greater consumption utility coefficient $(\theta)$ increases all the steady state values. Moreover, the linear-quadratic specification of preferences implies that at the optimal steady state, all steady state variables are proportional to $\theta$. Qualitatively, an increase in $\theta$ boosts the marginal utility of consumption, which increases consumption and the stock of waste. This in turn stimulates recycling. The total impact on capital depends on income generation through recycling and consumption rise. In our case, it is positive. Finally, a greater waste disutility coefficient $(e)$ lowers the steady-state waste stock and does not affect the steady state capital stock. Note that if the waste disutility coefficient is lower than the recycling disutility coefficient, i.e., $e<1$, the steady-state waste stock increases. Regarding the discounting rate $(r)$, it has no influence on the steady-state capital stock but has a positive effect on the steady-state waste stock. This property is mainly due to the linear-quadratic preferences: abstracting away from waste and recycling, the AK model with quadratic preferences will deliver long-term consumption and capital levels which only depend on productivity (parameter $a$ ) and the bliss point $\theta$. Adding waste and recycling does not modify this property. However, as the 
discounting rate increases, leading to a larger preference for the present, consumption will increase along the transition, inducing an increment in the stock of waste in the long-run.

\section{Dynamics}

We now investigate the structure of the associated stable manifolds.

Proposition 2. The steady state exhibits a (local) two-dimensional stable manifold.

Proof. See Appendix A4.

Therefore, for a sufficiently patient social planner, a saddle-point can be reached. We can prove that convergence can only be monotonic.

Proposition 3. Convergence from a close neighborhood to the steady state is monotonic.

Proof. See Appendix A5.

According to Proposition 3, consumption-based waste should not exhibit spiraling convergence to the locally stable steady state. The control paths can be characterized as follows.

Lemma 6. An interior optimal solution satisfies the following system of equations:

$$
\begin{aligned}
& \ddot{c}=r \dot{c}+a(r-a) G e^{(r-a) t}+\beta e(\beta c-v) \\
& \ddot{v}=r \dot{v}-a \varphi(r-a) G e^{(r-a) t}-e(\beta c-v)
\end{aligned}
$$

Proof. See Appendix A6.

This general case is solvable numerically.

Proposition 4. For $\beta=1$, we get:

$$
\begin{aligned}
& c(t)=\frac{1}{2}\left\{\theta+C_{3} e^{\frac{1}{2}\left(r-\sqrt{r^{2}+4 e}\right) t}-\left[(1-\varphi)+\frac{a(1+\varphi)(r-a)}{a(r-a)+e}\right] G e^{(r-a) t}\right\} \\
& v(t)=\frac{1}{2}\left\{\theta-C_{3} e^{\frac{1}{2}\left(r-\sqrt{r^{2}+4 e}\right) t}+\left[\frac{a(1+\varphi)(r-a)}{a(r-a)+e}-(1-\varphi)\right] G e^{(r-a) t}\right\}
\end{aligned}
$$

whose constants of integration can be found explicitly. Letting $\varphi<1$, then for $G>0(G<0)$, the sum $c(t)+v(t)$ increases (decreases) monotonically and concavely (convexly) to converge to $\theta$ when $t \mapsto \infty$. The difference $c(t)-v(t)$ decreases to zero when $t \mapsto \infty$.

Proof. See Appendix A7. 
Clearly, if $W(0)>(<) W^{S}$, then $G>(<) 0$ to ensure convergence to the steady state.

\subsection{Production-based waste generation}

In this case, we assume that $\alpha>0$ and $\beta=0$ in the law of motion of polluting waste (3).

\section{Optimality}

Skipping the time index for convenience, the current-value Hamiltonian is:

$$
H=c\left(\theta-\frac{c}{2}\right)-\frac{e W^{2}}{2}-\frac{v^{2}}{2}+\lambda(a K-c+\varphi v)+\mu(\alpha a K-v)
$$

where $\lambda \equiv \lambda(t)$ and $\mu \equiv \mu(t)$ are costate variables, $j=1,2$, that, if the state constraints are not binding, evolve according to:

$$
\begin{aligned}
& \dot{\lambda}=(r-a) \lambda-\mu \alpha a \\
& \dot{\mu}=r \mu+e W
\end{aligned}
$$

Assuming interior solutions, necessary conditions for optimality are:

$$
\begin{aligned}
& H_{c}=\theta-c-\lambda=0 \Rightarrow c=\theta-\lambda \\
& H_{v}=-v+\lambda \varphi-\mu=0 \Rightarrow v=\lambda \varphi-\mu
\end{aligned}
$$

From (18), the greater the implicit price of the capital stock, the lower the consumption rate. In (19), the greater the implicit price of the capital stock and the implicit cost of the waste stock, the greater the recycling effort. These results are intuitive.

Lemma 7. The necessary conditions are sufficient for optimality.

Proof. See Appendix A8.

Here also, the sufficient conditions used are true only for interior solutions.

Lemma 8. Let the state constraint $W \geq 0$ be non-binding. Then, it always holds that $\mu<0$.

Proof. See Appendix A9.

From now on, we concentrate on the interior solutions, and just like in the previous section on consumption-based waste, we go through the main steady state and dynamics issues. To unburden the presentation, we shall be briefer than in the previous section.

Steady state

Plugging the value of $c$ and $v$ from (18) and (19) in (2) and (3), respectively, the equations: 


$$
\begin{aligned}
\dot{K} & =a K-(\theta-\lambda)+\varphi(\lambda \varphi-\mu) \\
\dot{W} & =\alpha a K-\lambda \varphi+\mu
\end{aligned}
$$

along with (16) and (17), form the canonical system in the state-costate space.

Proposition 5. For $r<a$, the steady state is feasible and unique, given by:

$$
\begin{aligned}
& \left(\begin{array}{llll}
K^{S} & W^{S} & c^{S} & v^{S}
\end{array}\right)^{T}= \\
& {\left[\frac{\theta[(1+\varphi \alpha) a-r]}{a\left\{(1+\varphi \alpha)[(1+\alpha \varphi) a-r]+\alpha^{2} a\right\}} \frac{r \alpha \theta(a-r)}{e\left\{(1+\varphi \alpha)[(1+\alpha \varphi) a-r]+\alpha^{2} a\right\}} \frac{\theta(1+\varphi \alpha)[(1+\alpha \varphi) a-r]}{(1+\varphi \alpha)[(1+\alpha \varphi) a-r]+\alpha^{2} a} \frac{\alpha \theta[(1+\alpha \varphi) a-r]}{(1+\varphi \alpha)[(1+\alpha \varphi) a-r]+\alpha^{2} a}\right]}
\end{aligned}
$$

Proof. See Appendix A10.

As it transpires from the expressions of the steady state values given above, the model with capital-based or equivalently production-based waste involves more complex relationships because capital accumulation is not only the main engine of income in this economy, it is also the generator of waste, which cause the negative environmental externality and fosters recycling. Henceforth the corresponding comparative statics are more complicated. From (22), we observe that the marginal wasting coefficient of production $(\alpha)$ decreases as expected the long-run capital stock, waste stock and consumption flow. More interesting comparative statics are with respect to parameter, which are common to the consumption-based waste and production-based waste models. Let us consider parameter $\varphi$ for example. Greater marginal revenue from recycling $(\varphi)$ increases the long-run consumption, which in turn decreases the long-run capital stock. As a consequence, the long-run waste stock and recycling effort are both reduced. When $\varphi$ goes up, consumption seems to play a long-term stabilizing role on the stock of waste. This is not the case in the model with consumption-based waste where the recycling effort, while increasing with $\varphi$ in the short-run, ends up independent of this parameter in the long- run.

The second common parameter example is the discounting rate $(r)$ : it has a negative impact on the long-run capital stock, consumption rate and recycling effort but a positive effect on the longrun waste stock. Recall that in the consumption-based waste case, it only affects (positively as in the current case) the stock of waste. In the model with production-based waste, the stationary capital ends up decreasing with the discount rate as in the traditional Ramsey model.

\section{Dynamics}


We now move to the stability analysis and investigate the structure of the stable manifolds.

Proposition 6. The steady state exhibits a (local) two-dimensional stable manifold.

Proof. See Appendix A11.

We now highlight an interesting property of the optimal growth model with production-based waste. We show hereafter that under certain conditions, it may give rise to an oscillatory convergence to the steady state, which is not granted in the case of consumption-based waste (see Proposition 3).

Proposition 7. For any given $r, a, e$, and $\theta$, there exists a threshold $\tilde{\alpha}>0$ such that for any $\alpha>(<) \tilde{\alpha}$, the convergence to the steady state is oscillatory (monotonic). Similarly, for any given $r, a, e$, and $\theta$, there exists a threshold $\tilde{\varphi}>0$ such that for any $\varphi>(<) \tilde{\varphi}$, the convergence to the steady state is oscillatory (monotonic).

Proof. See Appendix A12.

According to Proposition 7, convergence to the saddle-point is either monotonic or oscillatory, depending on the magnitude of the wasting impact of the revenue-generation process and the marginal impact of the recycling effort on capital accumulation. Therefore, oscillating convergence to the steady state can be caused either by highly wasteful production, which reflects the use of dirty technology (Stokey, 1998), or by highly CIR, which mirrors the absence of any depreciation of scrap recovery (Martin, 1982), that is, a highly effective recycling process.

\subsection{A preliminary comparison result}

In the next section, we shall go a step further and determine the main differences between consumption and production-based polluting waste, on the one hand, and CNR and CIR efforts, on the other hand, on capital growth and polluting waste accumulation in terms of both the steady state and the transient path, using both analytical and numerical results. Before, and based on our analytical results for consumption and production-based polluting waste, we make an important comparison.

Proposition 8. For $\varphi=0$ and $\alpha=\beta>0$, it holds that:

$$
c_{\mid \beta>0}^{S}>c_{\mid \alpha>0}^{S}
$$




$$
\begin{aligned}
& v_{\mid \beta>0}^{S}>v_{\mid \alpha>0}^{S} \\
& K_{\mid \beta>0}^{S}>K_{\mid \alpha>0}^{S} \\
& W_{\mid \beta>0}^{S}>W_{\mid \alpha>0}^{S}
\end{aligned}
$$

Proof. See Appendix A13.

Therefore, for CNR efforts, i.e., $\varphi=0$, and equivalent wasting impact coefficients, i.e., $\alpha=\beta>0$, the steady-state consumption level is greater if the polluting waste is a by-product of consumption rather than of production. Because $c_{\mid \beta>0}^{S}<\theta$ and $c_{\mid \alpha>0}^{S}<\theta$, the steady-state consumption is lower than the utility-maximizing consumption level under both production and consumption-based waste. For similar conditions, it follows that the steady-state capital stock is greater under consumption-based waste than under production-based waste. The two latter properties are important and thus deserve a careful interpretation. Why could it be that under consumption-based waste the central planner reaches larger consumption and capital stock levels than under production-based waste? When only consumption generates waste, two effects are at work: on one hand, consumption is directly driven down (with respect to the case $\beta=0$ ) as it decreases utility via waste; but on the other hand, a drop in consumption increases savings and capital accumulation, which in turn pushes consumption up (income effect). When waste is generated through production, there is an explicit brake on capital accumulation induced by the environmental negative externality, which limits both capital accumulation and therefore consumption. In turns out that this mechanism (brake on capital accumulation) is inactive under consumption-based waste. As a result, both the long-term consumption and capital stock are higher in the latter case.

Note also that due to $\beta\left[(a-r)+\alpha^{2} a\right]>\left(1+\beta^{2}\right) \alpha(a-r)$ when $\alpha=\beta$, the steady-state values of the waste stock and the recycling efforts are lower under production-based waste than under consumption-based waste. This comes as a natural consequence of the above mentioned properties for equal marginal waste generation coefficients $(\alpha=\beta)$ : since both consumption and capital stock levels are lower under production-based waste, the resulting stock of waste, and therefore the optimal recycling effort (under $\varphi=0$ ), are lower. 
Unfortunately, it is impossible to come out with complete analytical comparison results for any $\alpha, \beta$ and $\varphi$. Some numerical experiments are conducted hereafter to complement this early analytical section.

\section{Economic explorations}

We now get back to the main research questions stated in the introduction and answer them. We shall in particular investigate how consumption versus production-based polluting waste affect the interaction between capital growth and polluting waste accumulation (thus the emergence of an EKC path), and the role of the CIR versus the CNR assumption in the mechanisms involved. To this end, we use numerical experiments.

\subsection{Numerical strategy and calibration}

To compute the solution paths, we use a dynamic programming approach (see Appendix A17). The model is calibrated as depicted in Table 1 just below:

\begin{tabular}{|c|c|c|c|c|c|c|}
\hline$r$ & $a$ & $\alpha$ & $\beta$ & $\varphi$ & $\theta$ & $e$ \\
\hline 0.05 & 0.1 & $(0,0.5,4)$ & $(0,0.5)$ & $(0,0.1,10)$ & 1 & 1 \\
\hline
\end{tabular}

Tab. 1. Parameter values

The values in Table 1 reflect a situation where the marginal revenue from the capital stock ( $a=0.1$ ) is greater than the discounting rate $(r=0.05)$. The range of values selected for $\alpha, \beta$ and $\varphi$ aims to contrast some important configurations, that is, production-based vs. consumptionbased waste (i.e., $\alpha=0.5$ vs. $\beta=0.5$ ), on the one hand, and CIR vs. CNR efforts (i.e., $\varphi=0.1$ vs. $\varphi=0$ ) on the other hand. In addition, two special cases inducing oscillatory convergence to the steady state are considered, that is, highly wasteful production processes (i.e., $\alpha=4$ ) and highly CIR (i.e., $\varphi=10$ ). Finally, we assume equivalent parameter values for the disutility coefficient of waste and the disutility coefficient of recycling (i.e., $e=1$ ) so that the tradeoff between waste and recycling does not stem from arbitrary decisions concerning parameter values.

To assess the sensitivity of the solutions to the initial conditions, we assume in the cases with monotonic convergence two initial values for each state variable, that is, small and large (i.e., smaller and larger than the steady-state value), with $K_{0}=(6,10)$ and $W_{0}=(0,1)$.

The steady state values are reported in Table 2. All things being equal, the long-run capital stock and consumption are greater under consumption-based than production-based waste. Despite greater recycling efforts, the long-run waste is greater under consumption-based than production- 
based waste. On the other hand, the steady-state capital stock is greater under capital-neutral than CIR while the steady-state waste stock is similar under consumption-based waste and greater under production-based waste. Although CIR limits capital growth more than CIR does, it promotes a slightly cleaner environment only under production-based waste.

\begin{tabular}{|c|c|c|c|c|c|c|}
\hline & \multicolumn{2}{|c|}{$\begin{array}{c}\text { Consumption-based waste } \\
\alpha=0, \beta=0.5\end{array}$} & \multicolumn{2}{|c|}{$\begin{array}{l}\text { Production-based waste } \\
\qquad \alpha=0.5, \beta=0\end{array}$} & \multicolumn{2}{|c|}{$\begin{array}{l}\text { Production and consumption-based waste } \\
\qquad \alpha=0.5, \beta=0.5\end{array}$} \\
\hline & $\operatorname{CIR}(\varphi=0.1)$ & $\operatorname{CNR}(\varphi=0)$ & $\operatorname{CIR}(\varphi=0.1)$ & $\operatorname{CNR}(\varphi=0)$ & $\operatorname{CIR}(\varphi=0.1)$ & $\operatorname{CNR}(\varphi=0)$ \\
\hline$K^{S}$ & 7.600000005 & 8.00000001 & 6.646525675 & 6.666666669 & 3.935969865 & 4.000000000 \\
\hline$W$ & 0.02000000035 & 0.0200 & 0.01510574012 & 0.016 & 0.0 & $0.01 \mathrm{~s}$ \\
\hline$c^{S}$ & 0.8000000009 & 0.8000000013 & 0.697885196 & 0.6666666667 & 0.4350282485 & 0.4000000000 \\
\hline$v^{S}$ & 0.4000000006 & 0.4000000007 & 0.3323262837 & 0.3333333334 & 0.4143126174 & 0.3999999998 \\
\hline
\end{tabular}

Table 2 State and control steady-state values under focal configurations

To unburden the presentation and ease the comparison between the different mechanisms involved, we shall study the induced optimal paths and welfare outcomes first under consumption-based waste, then under production-based waste.

\subsection{Optimal time paths and implied welfare under consumption-based waste}

\subsubsection{Transient dynamics}

Figure 1 illustrates the paths converging to the steady state from various initial conditions under consumption-based waste for CIR (1.a) and CNR (1.b) efforts. The transient paths are drawn with a dot (long dash) line for initially low (high) capital and waste stocks, and a dot dash (solid) line for initially high (low) capital stock and low (high) waste stock.

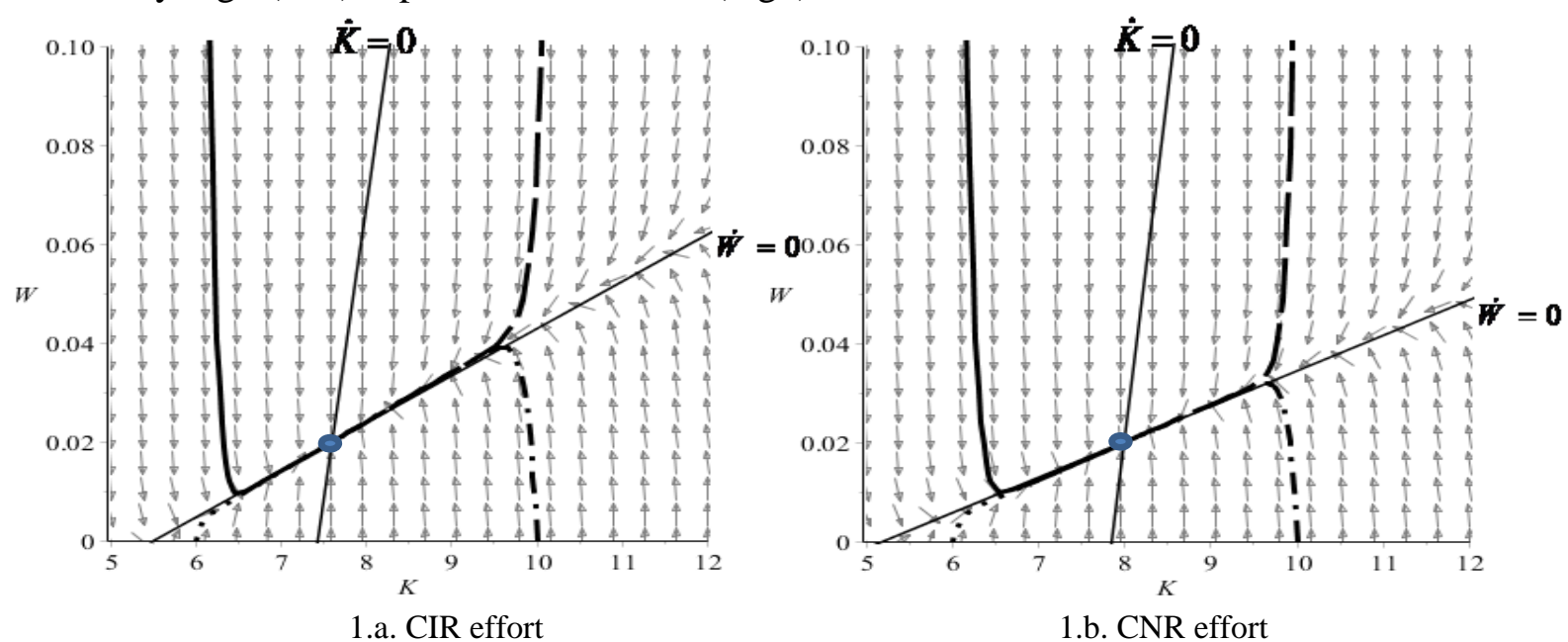

Fig. 1 Phase-portrait diagrams in the state space for consumption-based waste

The optimal path is composed of two arcs corresponding to sequential sets of actions, that is: 
- From both initially high (low) state values, the optimal policy consists in first decreasing (increasing) the waste stock rapidly and the capital stock slowly, and then decreasing (increasing) both the capital and waste stocks at a similar pace until the steady state is reached.

- From initially high (low) capital stock and high (low) waste stock, the optimal policy is first to decrease (increase) the waste stock rapidly and the capital stock slowly, and then to decrease (increase) the capital and waste stocks at a similar pace toward the steady state.

Overall, the second arc, which arises beyond the turning point and characterizes the longest portion of the planning horizon, essentially depicts a mutual complementarity between the capital stock and the waste stock. That is, under consumption-based waste, capital and pollution most often either increase or decrease together. This result lets us identify initial conditions for which the first arc, located before the turning point, would exhibit (transient) mutual substitutability between the capital and waste stocks, i.e., an EKC-like arc.

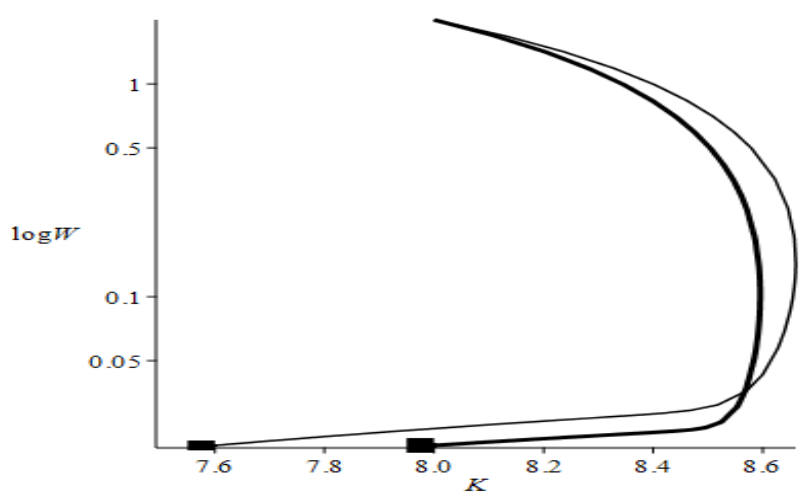

Fig. 2 EKC-like state path for consumption-based waste under CIR (thin line) and CNR (bold line) efforts with logarithmic scale for waste stock

We find that such initial conditions exist (Figure 2): for both CIR and CNR, capital growth allows a cleaner environment from initially intermediate (i.e., near the steady-state value) capital stock and very large waste stock, e.g., $\left(K_{0}, W_{0}\right)=(8,2)$, but only for limited time interval. The substitutability between the two stocks is more marked for CIR than for CNR, as in the subsequent complementarity, which allows greater contraction of the capital stock.

\begin{tabular}{|l|c|c|}
\cline { 2 - 3 } \multicolumn{1}{c|}{} & Low initial capital stock & High initial capital stock \\
\hline $\begin{array}{l}\text { High initial } \\
\text { waste stock }\end{array}$ & $\begin{array}{c}\text { Initially low, increasing consumption and } \\
\text { initially intermediate, decreasing then } \\
\text { increasing (undershooting) recycling efforts }\end{array}$ & $\begin{array}{c}\text { Initially high, increasing then decreasing } \\
\text { (overshooting) consumption and initially high, } \\
\text { decreasing recycling efforts }\end{array}$ \\
\hline $\begin{array}{l}\text { Low initial } \\
\text { waste stock }\end{array}$ & $\begin{array}{c}\text { Initially low, increasing consumption and } \\
\text { recycling efforts }\end{array}$ & $\begin{array}{c}\text { Initially high, decreasing consumption and } \\
\text { initially intermediate, decreasing recycling efforts }\end{array}$ \\
\hline
\end{tabular}

Tab. 3 Optimal patterns of consumption and recycling efforts for consumption-based waste

The optimal consumption and recycling effort policies' time paths corresponding to the various 
paths in Figure 1 are shown in Figure 3. The patterns of optimal consumption and recycling efforts obtained for the various initial conditions are summarized in Table 3.

From both initially low state values, the optimal policy consists in setting initially low consumption and recycling efforts during a brief time period and then raising both efforts slowly until their respective steady-state values are reached. The reason is that initially low consumption results in quickly increasing capital stock and slowly increasing waste stock. Relatedly, recycling efforts are initially very low, which allows a greater increase of waste stock than of capital stock. Afterward, both control variables steadily increase until their steady-state values are reached. In this context, consumption and recycling effort work as mutual complements, i.e., recycling directly supports consumption by preventing excessive polluting waste externalities. This trend is also observed for the case of initially high capital stock and initially low waste stock: in this case, however, initial consumption is high and initial recycling efforts are intermediate, and both variables decrease after a brief time period to reach the steady state.

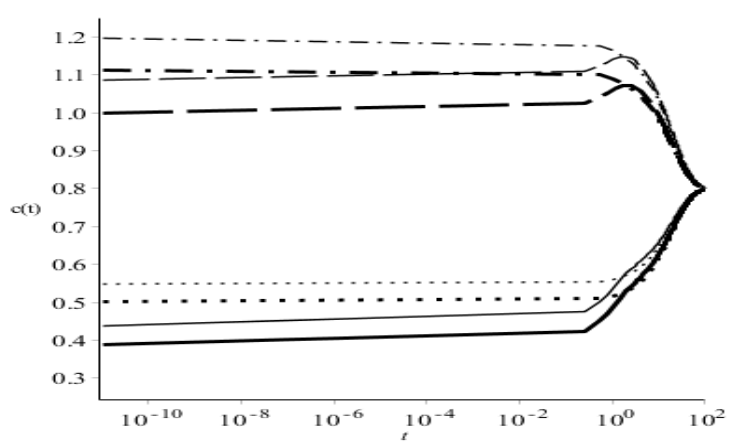

3.a. Consumption

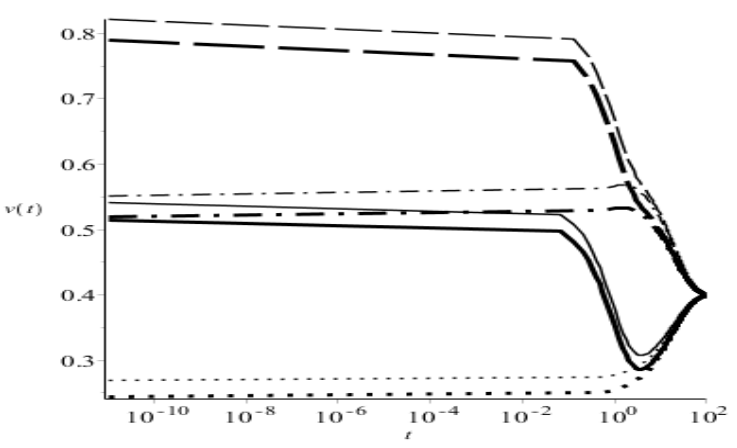

3.b. Recycling effort

Fig. 3 Control paths for consumption-based waste under CIR (thin line) and CNR (bold line) efforts (log. time scale) The initial recycling efforts are at their highest level for both initially high stocks of capital and waste, while consumption is clearly lower than for initially high capital stock and low waste stock. The reason is that more recycling and less consumption are initially needed to quickly reduce the initial waste stock. Overall, the greater the initial waste stock, the lower the consumption level. Note however that the initial capital stock has a stronger influence than the initial waste stock on the consumption level. In contrast, the recycling efforts are significantly positively influenced by both initial state values. However, the influence of the initial value of the capital stock is prevalent. An interesting feature nevertheless associated with a high initial waste stock is a non-monotonic behavior, i.e., undershooting of recycling efforts linked to initially low capital stock and overshooting of consumption due to initially high capital stock. This behavior, which is due to the waste stock being initially far from its steady state value, is particularly 
marked in the case of initially low capital stock and high waste stock for which consumption and recycling efforts are first briefly mutual substitutes and then become mutual complements.

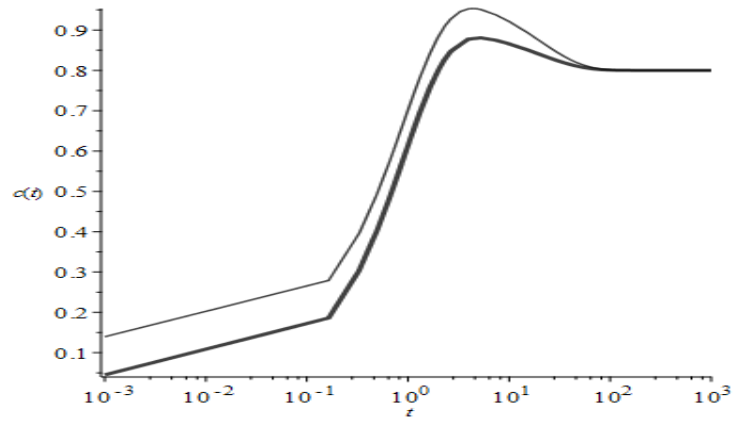

4.a. Consumption

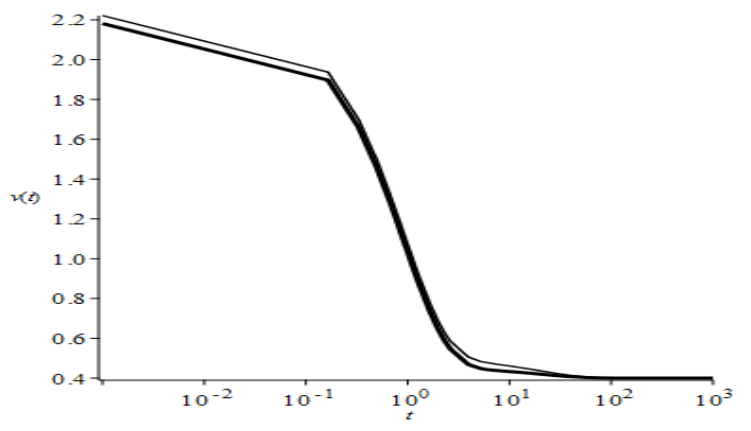

4.b. Recycling effort

Fig. 4 Control paths related to EKC-like path for consumption-based waste under CIR (thin line) and CNR (bold line) efforts (log. time scale)

In the specific case of initially intermediate capital stock and very large waste stock, e.g., $\left(K_{0}, W_{0}\right)=(8,2)$, which allows for substitutability between the stocks of capital and waste, i.e., EKC-like path, the optimal policy also exhibits overshooting, predominantly with substitutability between the control variables, i.e., consumption should be initially low and increasing while recycling efforts should be initially high and decreasing over time, as suggested in Figure 4. Finally, in all cases, when recycling does not add to capital growth, consumption is lower than in the converse case, which thus makes recycling efforts less necessary. These patterns indicate that recycling indirectly supports consumption as long as the recycling process remains effective.

\subsubsection{Welfare implications}

In Figure 5, the welfare function is computed for different time horizons to characterize its transient evolution. Apparently, lower initial waste stock results in higher welfare. In the case of CIR, the welfare is greater with lower than with higher initial capital stock. The reason is that recycling and polluting waste externalities arising from greater consumption generate more disutility from higher than lower initial capital stock. Under CNR, the differences in welfare between lower and higher initial capital stock vanish because of the lower reduction of recycling and waste externalities in the latter case. However, lower welfare is obtained with higher initial waste stock. Overall, social welfare is greater with cleaner rather than wealthier initial conditions. Compared with CIR, CNR is welfare-improving in the case of higher initial capital stock because lower consumption under CNR than CIR entails less costly pollution and recycling negative externalities. In contrast, welfare is quite similar between CIR and CNR in the case of low initial capital stock due to the initially low and increasing consumption path induced. 


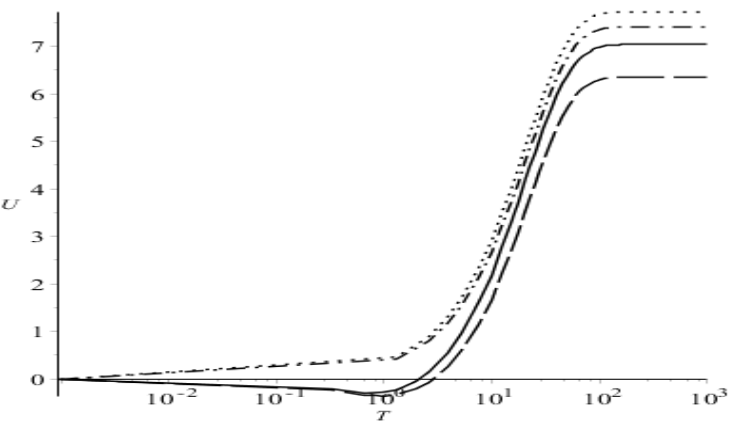

5.a. CIR

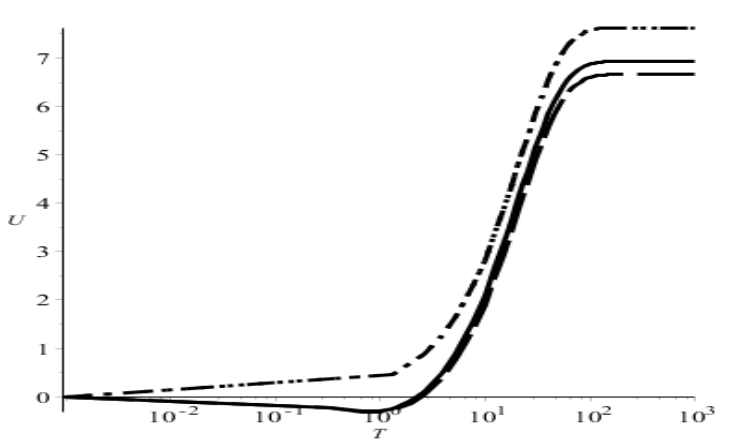

5.b. CNR

Fig. 5 Social welfare for consumption-based waste under CIR (thin line) and CNR (bold line) efforts (log. time scale) Welfare is also very similar between CIR and CNR for very high initial waste stock, as in the case of the EKC-like path for which consumption is also initially low and increasing (Figure 6). In all cases, a greater initial waste stock is more harmful to the transient welfare.

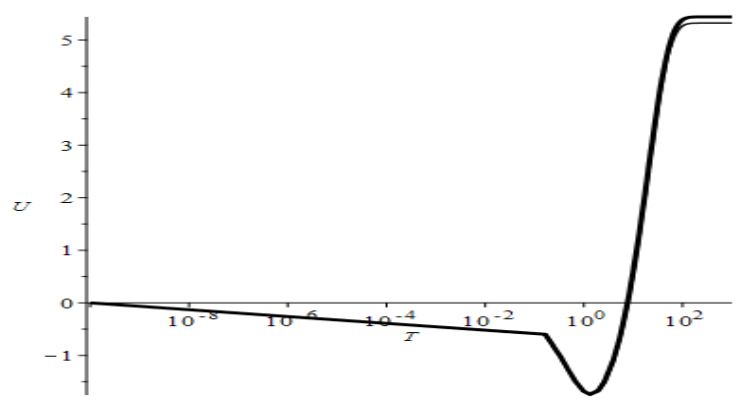

Fig. 6 Social welfare related to EKC-like state path for consumption-based waste under CIR (thin line) and CNR (bold line) efforts (log. time scale)

\subsection{Optimal time paths and implied welfare under production-based waste}

\subsubsection{Transient dynamics}

We now turn to the case of production-based waste. The phase-portrait diagrams in Figure 7 show the paths converging to the steady state from various initial conditions for CIR and CNR (resp., 7.a and 7.b). Apart from lower steady state values of the state variables and slightly weaker complementarity relationship between the two stocks, the patterns do not seem to differ much from those of consumption-based waste.

However, the initial conditions under which mutual substitutability exists between the stocks of capital and waste, i.e., EKC-like path, are different from those related to consumption-based waste (Figure 8). That is, a lower initial capital stock and larger waste stock than for consumption-based waste, i.e., $\left(K_{0}, W_{0}\right)=(7,3)$, are now required for capital growth to allow a transiently cleaner environment but over a smaller interval. However, the arc of substitutability between the stocks of capital and waste does not exist for CNR even for much higher initial waste 
stock. Thus, complementarity always prevails under production-based waste with CNR, which leads to less severe contraction of capital but also less effective depollution than under CIR.

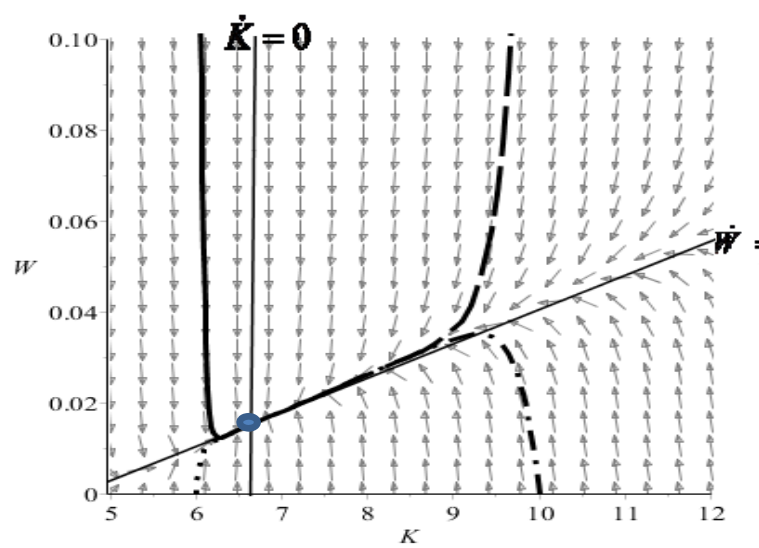

7.a. CIR effort

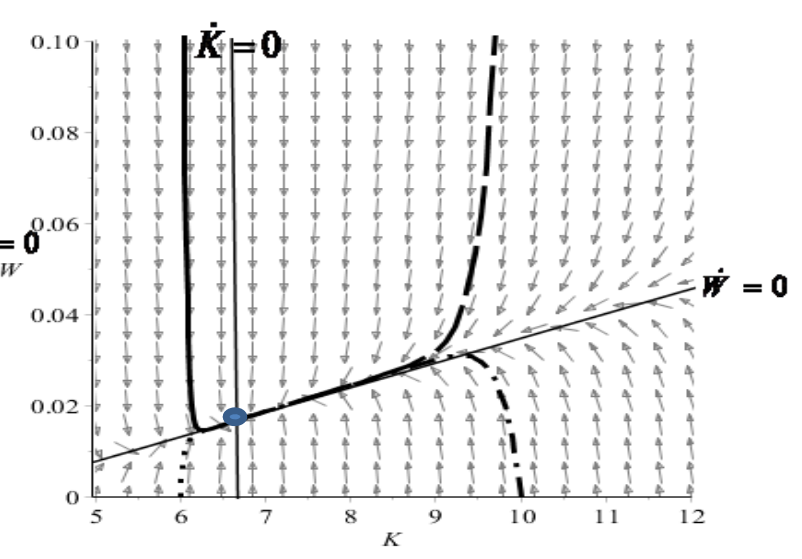

7.b. CNR effort

Fig. 7 Phase diagram in the state space for production-based waste

The optimal consumption and recycling effort policies related to the different paths in Figure 7 are shown in Figure 9. Here again, higher consumption results from higher initial capital stock. Consumption is also positively affected by the initial waste stock, albeit to a lesser extent. This is in contrast with the consumption-based waste case because consumption here is a non-costly, welfare-improving mean to reduce the waste stock via a capital decrease.

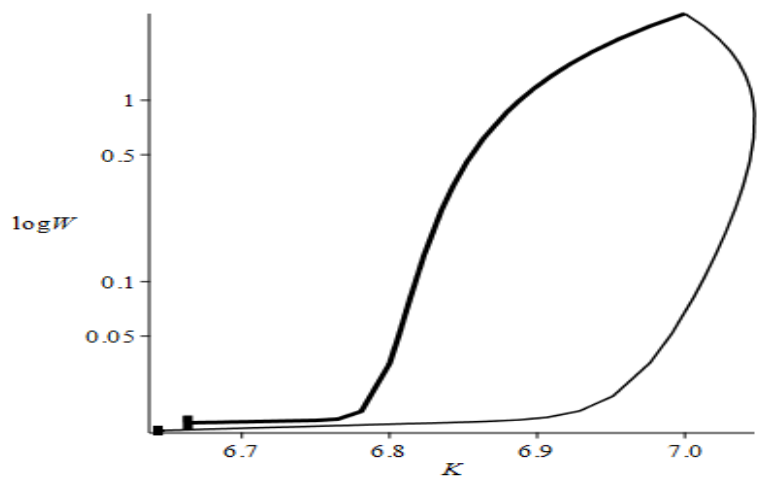

Fig. 8 EKC-like state path for production-based waste under CIR (thin line) and CNR (bold line) efforts with logarithmic scale for waste stock

Another important difference from the case of consumption-based waste is that recycling is positively influenced by the waste stock. A third important difference from the case of consumption-based waste lies with the fact that while consumption is lower under CNR than CIR efforts, the recycling efforts are now slightly greater from initially high capital and lower or similar from initially low capital. 


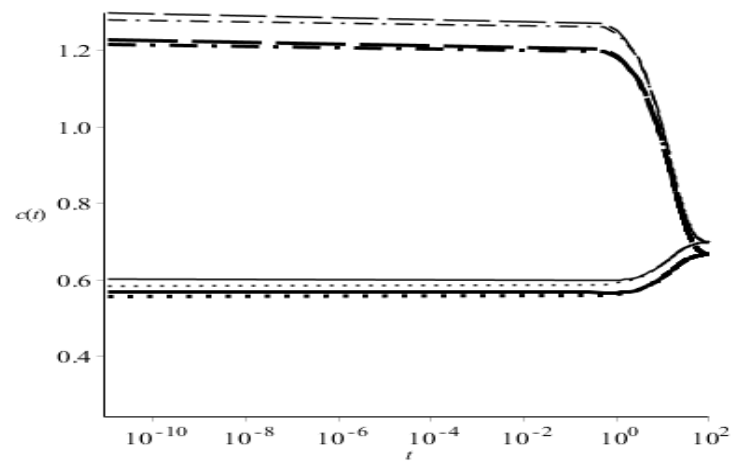

9.a. Consumption

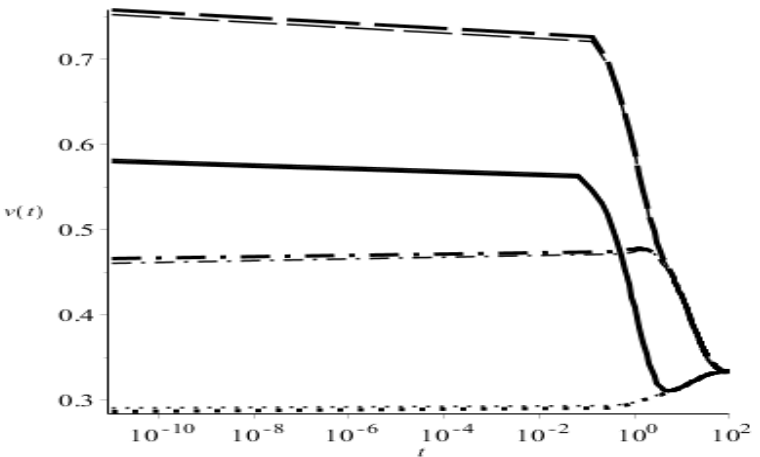

9.b. Recycling effort

Fig. 9 Control paths for production-based waste under CIR (thin line) and CNR (bold line) efforts (log. time scale) In the specific case of the EKC-like state path, the optimal policy is characterized by complementarity between the control variables, i.e., both consumption and recycling efforts should be initially high and decreasing over time, as suggested in Figure 10. When recycling is $\mathrm{CN}$, consumption is significantly lower than in the converse case, whereas the magnitude of recycling efforts remains unaffected.

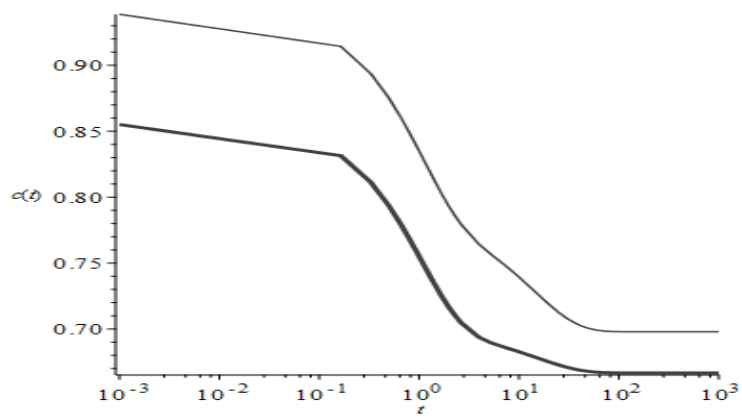

10.a. Consumption

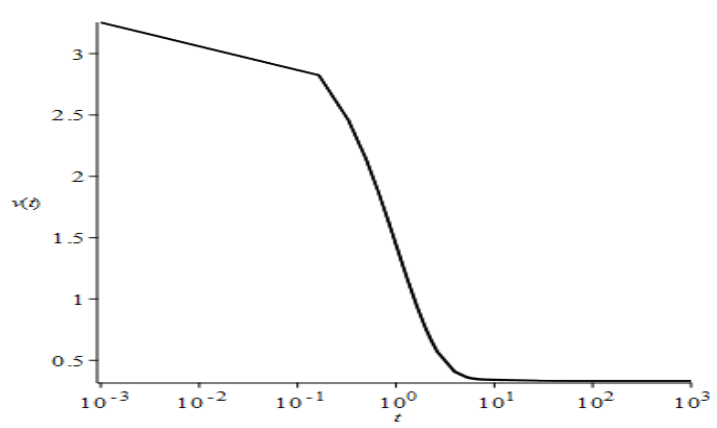

10.b. Recycling effort

Fig. 10 Control paths related to EKC-like path for production-based waste under CIR (thin line) and CNR (bold line)

\subsubsection{Welfare implications} efforts (log. time scale)

Figure 11 reports the social welfare associated with production-based waste, where higher welfare results from lower initial waste stock and to some extent from higher initial capital stock, while the lower welfare levels are obtained with initially higher waste stock. Despite higher consumption, initial conditions with both higher capital and waste stocks lead to lower welfare due to greater negative externalities resulting from higher recycling efforts. Again, the differences in welfare between lower and higher initial capital stock are more marked under CIR than CNR efforts, due to the greater reduction in consumption in the latter case between CIR and CNR for initially higher than lower capital stock. Finally, social welfare under CNR is similar to that under CIR from initially high capital but lower than that from initially low capital, mainly because slightly greater recycling efforts under CNR than CIR entail fewer pollution externalities. 


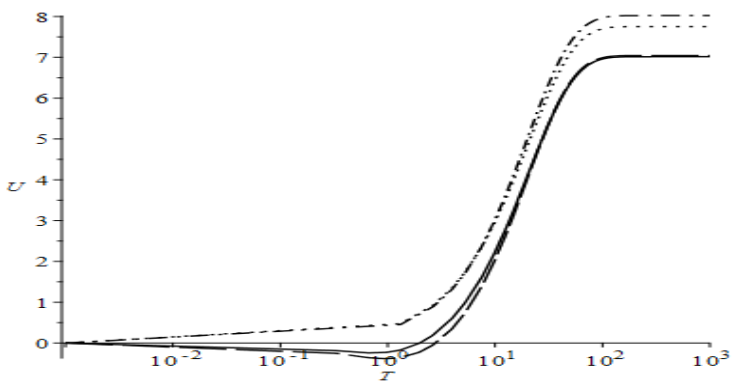

11.a. CIR

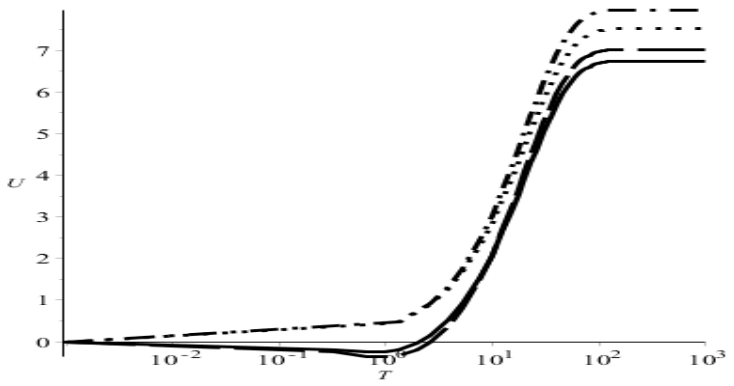

11.b. CNR

Fig. 11 Social welfare for production-based waste under CIR (thin line) and CNR (bold line) efforts (log. time scale) In the case of the EKC-like state path, the transient welfare is negative with quite low values (Figure 12), due to the initially high negative externalities generated by both high waste stock and recycling efforts. Afterwards, welfare becomes positive with a slightly greater value under CIR than under CNR because of a greater consumption level.

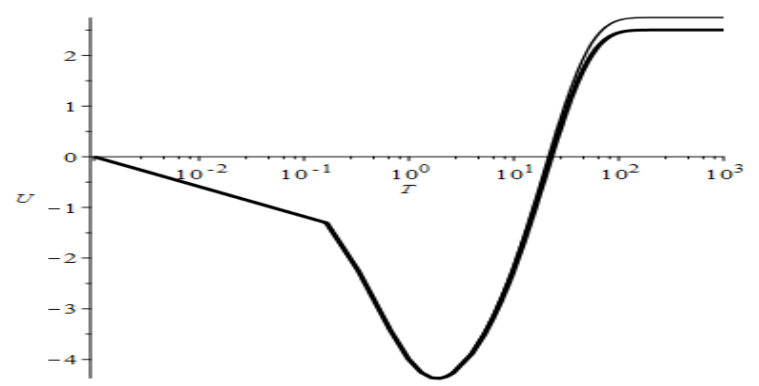

Fig. 12 Social welfare related to EKC-like state path for production-based waste under CIR (thin line) and CNR (bold line) efforts (log. time scale)

Comparing Figures 5 and 11, respectively, we observe that, for CIR, the welfare is greater under production-based waste than under consumption-based waste from initially high capital stock and similar welfare of production-based waste and consumption-based waste from low capital stock. In contrast, for CNR, the welfare is still greater under production-based waste than under consumption-based waste for initially high capital stock, but lower for initially low capital stock. Overall, production-based waste is more welfare-improving if the initial endowment in capital is high. The rationale behind this result is that although consumption-based waste exhibits a higher long-run consumption level for a high initial endowment in capital, it has lower consumption in the short run and tends to incur more negative externalities from both polluting waste and recycling than does production-based waste over the whole planning horizon. For a low initial endowment in capital, production-based waste is still associated with greater transient consumption than consumption-based waste is, but the transient differences in terms of cost of negative externalities from polluting waste and recycling efforts are now lower. 


\subsubsection{The case of oscillatory dynamics}

We now study two special cases related to production-based waste, for which the convergence to the steady state is oscillatory, due either to the wasting impact of the revenue generation process or to the marginal impact of the recycling effort on capital growth (see Proposition 3).

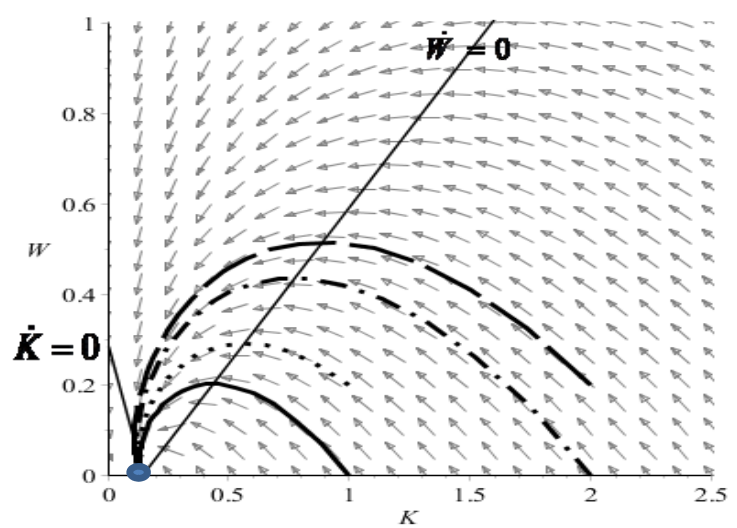

13.a. CIR effort

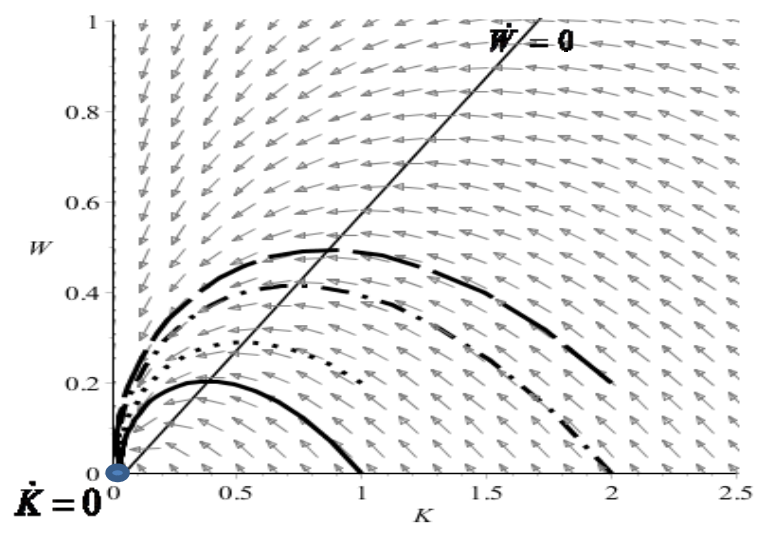

13.b. CNR effort

Fig. 13 Phase diagram in the state space for highly wasteful production

We first consider the case of highly wasteful production $(\alpha=4)$. In this case, we observe that any path starting with capital stock greater than its steady-state value first undergoes a phase of contraction of capital along with expansion of the waste stock and then a phase of contraction of the two stocks (Figure 13). Beyond the turning point, the capital decline results in a cleaner environment. Therefore, the dirtiest production technologies result in a total reversal of the EKC. Under an ineffective recycling process, i.e., CNR, the total reversal of the EKC is even more severe in terms of capital contraction.

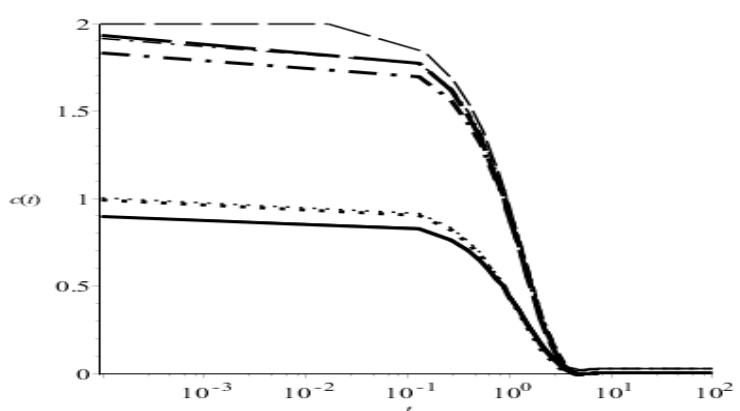

14.a. Consumption

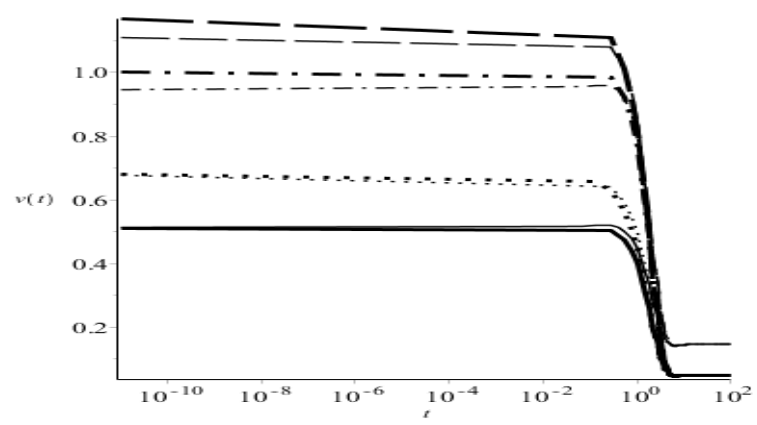

14.b. Recycling effort

Fig. 14 Control paths for highly wasteful production under CIR (thin line) and CNR (bold line) efforts (log. time scale)

In the context of total reversal of the EKC, the optimal policy is also characterized by complementarity between the control variables (Figure 14). When recycling does not add to capital, consumption is lower than in the converse case only if the initial stock of capital is sufficiently high. Under the latter condition, however, recycling efforts are greater under CNR 
than in the converse case. The rationale behind this result is that consumption under CIR is a substitute for recycling to reduce waste.

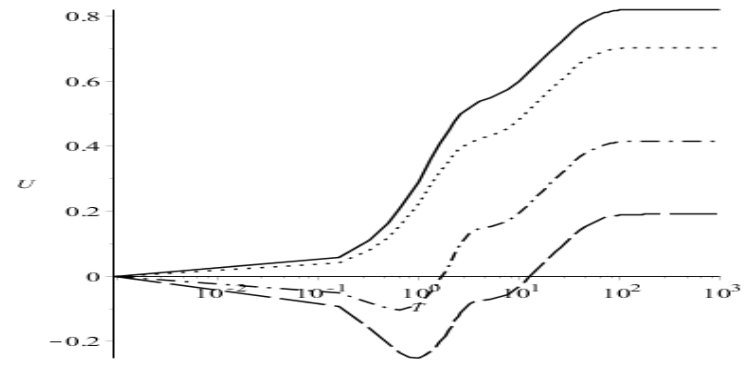

15.a. CIR

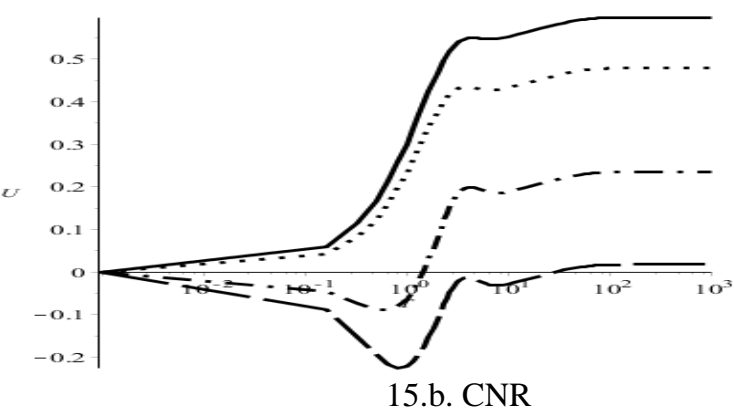

Fig. 15 Social welfare for highly wasteful production under CIR (thin line) and CNR (bold line) efforts (log. time scale)

In Figure 15, a higher welfare results from lower initial capital stock and to a lesser extent from lower initial waste stock. Again, despite higher consumption, initial conditions involving both higher stocks of capital and waste lead to lower welfare due to greater negative externalities resulting from higher recycling efforts. In contrast with the previous cases, welfare is now lower under CNR than under CIR. The reason is that fewer recycling negative externalities are observed under CIR due to greater consumption used to reduce waste.

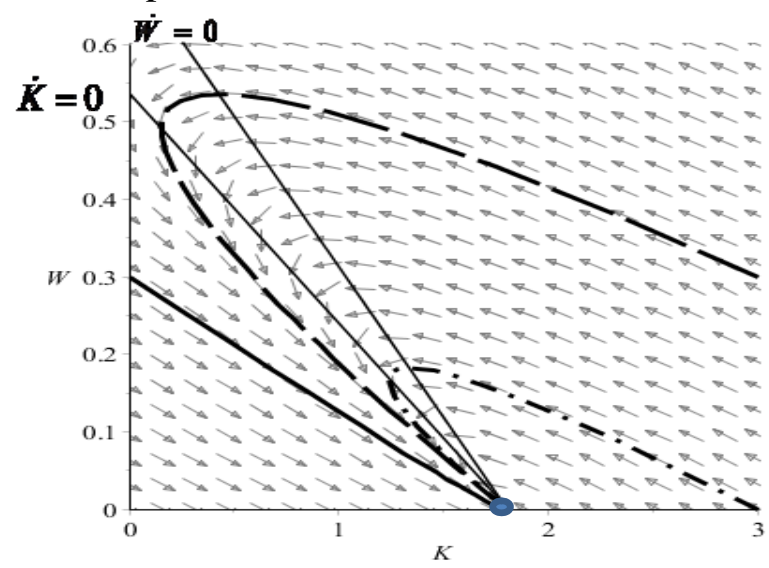

Fig. 16 Phase diagram in the state space for production-based waste under highly CIR

We finally analyze the case of highly CIR $(\varphi=10)$. Here, two main phases are observed, that is, a phase of contraction of capital along with expansion of the waste stock and then a phase of expansion of capital along with contraction of the waste stock (Figure 16). Beyond the turning point, capital growth allows a cleaner environment. Therefore, a highly effective recycling process leads to a partial reversal of the EKC. 

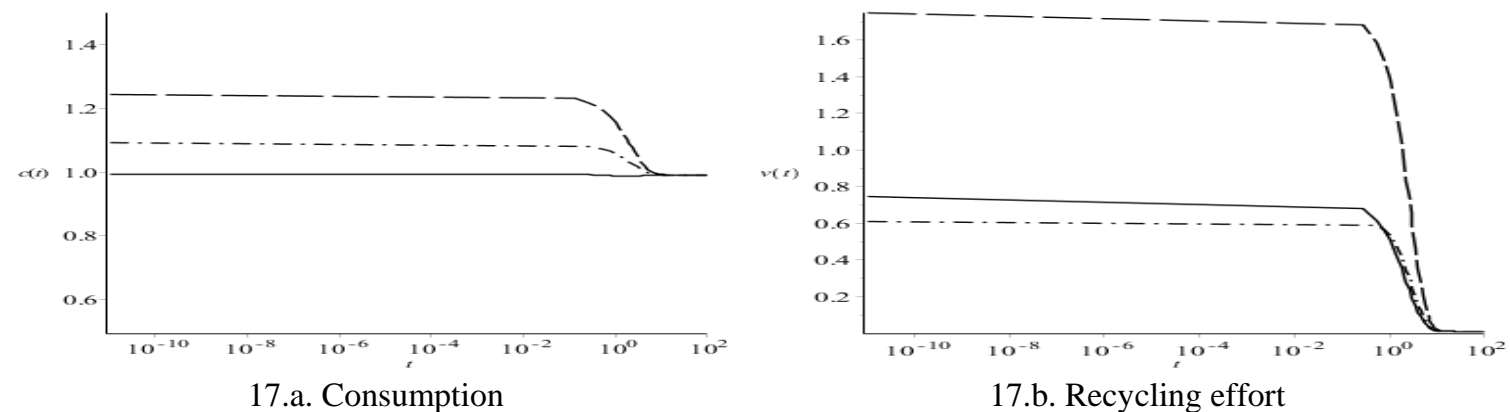

Fig. 17 Control time paths for production-based waste under highly CIR (log. time scale)

In the case of partial reversal of the EKC, the optimal policy is also based on complementarity between the control variables (Figure 17). Consumption and recycling are both positively affected by the initial capital stock and are affected to a lesser extent by the initial waste stock.

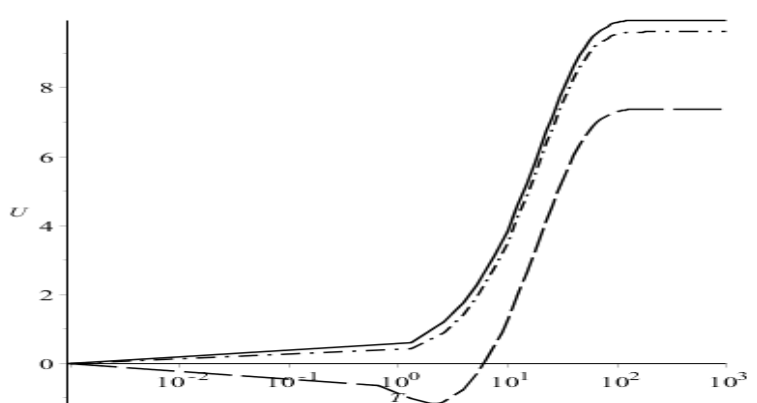

Fig. 18 Social welfare for production-based waste under highly CIR (log. time scale)

In Figure 18, higher welfare is derived from lower initial capital stock and to a lesser extent from lower initial waste stock. The ranking in terms of decreasing welfare is consistent with that of consumption, which in turn is allowed by the highly effective recycling efforts.

\section{Conclusion}

This paper seeks to determine which source of polluting waste among the stock of productive capital and consumption flows is the most detrimental in terms of welfare and environmental sustainability. We consider a capital accumulation model where either production or consumption is a source of polluting waste. Although the accumulation of the polluting waste cannot be naturally abated, it can be reduced by recycling efforts. To account for their effectiveness, recycling efforts may or may not benefit capital accumulation. The economic tradeoff, which involves instantaneous utility from consumption and instantaneous disutility from negative externalities due to polluting waste and recycling over infinite time horizon, allows us to identify the optimal recycling policy depending on the source of pollution and also to disclose the conditions of emergence of an Environmental Kuznets Curve path.

Our mathematical analysis shows that consumption and production as sources of polluting waste 
have quite different consequences on the interaction between capital and pollution accumulation. The main differences can be summarized as follows:

- Convergence from a close neighborhood to the unique interior, locally stable steady state is monotonic under consumption-based waste, but it can also be oscillatory under productionbased waste due either to very dirty technology of production or to highly effective recycling.

- To compare the long-term consequences of the optimal control of consumption versus production-based waste via recycling, we examine the implications of the benchmark case where one additional unit of consumption yields the same additional waste as a supplementary unit of production and recycling does not generate additional income. In this framework, the central planner reaches larger consumption and capital stock stationary values under consumption-based waste than under production-based waste. That's because in the latter there is an explicit brake on capital accumulation induced by the environmental negative externality, which limits both capital accumulation and therefore consumption. Such a mechanism does not under consumption-based waste.

- In the same analytical set-up, it is shown accordingly that the optimal control of waste allows to reach lower stocks of waste through lower recycling efforts in the production-based waste case. From extensive numerical analysis, we also gained further important insights:

- The analytical results above are shown to be robust under a set of alternative parameterizations where the assumptions adopted in the benchmark case are successively dropped.

- In countries with intermediate wealth and very large waste stock, an EKC-like arc exists under consumption-based waste, during which capital accumulation allows for a cleaner environment for both effective and ineffective recycling, but with ephemeral and reversible capital growth. In contrast, under production-based waste, a lower initial wealth and larger waste stock than for consumption-based waste are required for an EKC-like arc to arise, but this happens only for effective recycling and over a smaller interval.

- Under production-based waste involving very dirty technology, a total reversal of the EKC-like arc is observed. Under ineffective recycling, the reversal of the EKC is even more severe in terms of capital contraction. Finally, under production-based waste with highly effective recycling, a partial reversal of the EKC-like arc is obtained.

While most economic studies disregard the consequences of the differences between two pollution sources, namely production and consumption, on social welfare and environmental 
sustainability, our study suggests that, all things being equal, national regulations should focus on minimizing the wasteful impact of consumption in wealthy countries and the wasteful impact of production in the case of ineffective recycling in poor countries.

Our results can be further generalized by extending the model to a decentralized structure involving two non-cooperative countries with different pollution sources and different levels of effectiveness of their recycling process. An important issue related to this context is how the countries’ non-cooperative strategies affect both welfare and environmental sustainability.

\section{Appendix}

A1. The Legendre-Clebsch condition of concavity of the Hamiltonian wrt the control variables is satisfied, because the Hessian: $\left[\begin{array}{ll}H_{c c} & H_{c v} \\ H_{v c} & H_{v V}\end{array}\right]=\left[\begin{array}{cc}-1 & 0 \\ 0 & -1\end{array}\right]$ is negative definite. This guarantees a maximum of the Hamiltonian. Plugging the respective expressions of $c$ and $v$ from (7) and (8) in (4) results in the maximized Hamiltonian:

$$
H^{0}=(\theta-\lambda+\mu \beta)^{2} / 2+(\lambda \varphi-\mu)^{2} / 2+\lambda a K-e W^{2} / 2
$$

from which the Hessian matrix: $\left[\begin{array}{ll}H_{K K} & H_{K W} \\ H_{W K} & H_{W W}\end{array}\right]=\left[\begin{array}{cc}0 & 0 \\ 0 & -e\end{array}\right]$ is negative semi-definite. This ensures that the necessary conditions are also sufficient for optimality, which guarantees the existence of a globally optimal solution.

A2. The proof is by contradiction. Assume a time point $t$ such that the costate $\mu$ is non-negative and the transversality condition holds. Then, equation (6) implies that $\mu$ can grow only at a rate greater than $r$. Therefore, the transversality condition will never be met. Such a point cannot exist, i.e., $\mu<0$. The result for $\lambda$ is derived in a similar way. Because we assume that $r<a$, starting from any $\lambda(0), \lambda$ always tends to zero.

A3. Equating the RHS of (9)-(10)-(5)-(6) to 0 and solving by identification and substitution, we get $\lambda^{S}=0$ and $\mu^{S}=-\beta \theta /\left(1+\beta^{2}\right)$ and $K^{S}$ and $W^{S}$ as given in (11). Plugging these expressions in (7) and (8), respectively, and simplifying yields $c^{S}$ and $v^{S}$ in (11). From (11), it can be shown that the limiting transversality conditions are satisfied for the saddle-paths because:

$$
\begin{aligned}
& \lim _{t \mapsto+\infty} e^{-r t} \lambda(t) K(t)=0 \\
& \lim _{t \mapsto+\infty} e^{-r t} \mu(t) W(t)=\lim _{t \mapsto+\infty}\left[-r \beta^{2} \theta^{2} e^{-r t} / e\left(1+\beta^{2}\right)^{2}\right]=0
\end{aligned}
$$

This ensures the uniqueness of the globally optimal solution. $\square$

A4. To analyze the stability of the steady state, we compute the Jacobian of the canonical system (9)-(10)-(5)-(6):

$$
J=\left[\begin{array}{cccc}
a & 0 & 1+\varphi^{2} & -\beta-\varphi \\
0 & 0 & -\beta-\varphi & \beta^{2}+1 \\
0 & 0 & r-a & 0 \\
0 & e & 0 & r
\end{array}\right]
$$

Given that $\lambda$ and $\mu$ are evaluated at their steady state value, we compute the determinant:

$$
|J|=a e(a-r)\left(1+\beta^{2}\right)
$$

which has a positive value for $r<a$. Using Dockner's formula (Dockner, 1985), we determine the sum of the principal minors of $J$ of order 2 minus the squared discounting rate, that is: 


$$
\Psi=-a(a-r)-e\left(1+\beta^{2}\right)
$$

The necessary and sufficient conditions that ensure that two eigenvalues have negative real parts and two have positive real parts, which corresponds to the case of a two-dimensional stable manifold, are $|J|>0$ and $\Psi<0$. The sign of $\Psi$ is negative whenever $r<a$, which implies that a two-dimensional stable manifold (saddle-point) exists in the case of a sufficiently patient social planner.

A5. To determine whether the optimal path is monotonic or oscillatory, we compute the expression (Dockner, 1985):

$$
\Omega=\Psi^{2}-4|J|=\left[a(a-r)-e\left(1+\beta^{2}\right)\right]^{2}
$$

A positive (negative) sign of $\Omega$ indicates that convergence to the saddle-point is monotonic (spiraling) near the steady state. Because $\Omega>0$, the convergence to the saddle-point is monotonic near the steady state.

A6. Differentiating (7) wrt time, we get:

$$
\dot{c}=-\dot{\lambda}+\beta \dot{\mu}=-(r-a) \lambda+\beta(r \mu+e W)
$$

which, when differentiating again, leads to:

$$
\ddot{c}=-(r-a)^{2} \lambda+\beta[r(r \mu+e W)+e \dot{W}]
$$

Substituting $\beta(r \mu+e W)$ from (A5.1) and $\dot{W}$ from (3), we have:

$$
\ddot{c}=-(r-a)^{2} \lambda+r \dot{c}+r(r-a) \lambda+\beta e(\beta c-v)=r \dot{c}+a(r-a) \lambda+\beta e(\beta c-v)
$$

Similarly, from (8), we obtain:

$$
\dot{v}=\varphi(r-a) \lambda-(r \mu+e W)
$$

which, differentiated again, gives:

$$
\ddot{v}=\varphi(r-a)^{2} \lambda-[r(r \mu+e W)+e \dot{W}]=\varphi(r-a)^{2} \lambda+[r \varphi(r-a) \lambda-e(\beta c-v)]
$$

Thus, accounting for $\lambda(t)=G e^{(r-a) t}$, we get (13)-(14). The transient path converging to a steady state can then be found with the boundary conditions:

$$
\begin{aligned}
& \dot{v}(0)=\varphi(r-a) G-(r \mu(0)+e W(0)), \\
& \ddot{c}(0)=r \dot{c}(0)+a(r-a) G+\beta e(\beta c(0)-v(0)) \\
& \dot{c}(0)=-(r-a) G+\beta(r \mu(0)+e W(0)) \\
& \ddot{v}(0)=r \dot{v}(0)-a \varphi(r-a) G-e(\beta c(0)-v(0)) \\
& c(0)=\theta-G+\beta \mu(0) \\
& \ddot{c}(0)=-(r-a)^{2} \lambda+\beta[r(r \mu+e W(0))+e \dot{W}(0)] \\
& v(0)=\varphi G-\mu(0) \\
& \ddot{v}(0)=\varphi(r-a)^{2} \lambda-[r(r \mu+e W(0))+e \dot{W}(0)] . \\
& \dot{W}(0)=\beta c(0)-v(0)
\end{aligned}
$$

A7. Let $\beta=1$, then by introducing a new control variable, $y=c+v$, we have

$$
\dot{y}=-(1-\varphi)(r-a) G e^{(r-a) t}
$$

and therefore:

$$
y(t)=C_{1}-(1-\varphi) G e^{(r-a) t}
$$

where $c(0)+v(0)=y(0)=\theta-(1-\varphi) G=C_{1}-(1-\varphi) G$, i.e., $C_{1}=\theta$. Note that:

$$
C_{1}=y^{S}=c^{S}+v^{S}=\theta
$$

Similarly, introducing a variable $z=c-v$, we have:

$$
\ddot{z}=r \dot{z}+e z+a(1+\varphi)(r-a) G e^{(r-a) t}
$$

that is:

$$
\mathrm{z}(t)=e^{\frac{1}{2}\left(r+\sqrt{r^{2}+4 e}\right) t} C_{2}+e^{\frac{1}{2}\left(r-\sqrt{r^{2}+4 e}\right) t} C_{3}-a(1+\varphi)(r-a) G e^{-(a-r) t} /[a(r-a)+e]
$$


Under steady-state conditions, $C_{2}$ must be zero. Therefore, we have:

$$
z(t)=C_{2} \exp \left[\frac{1}{2}\left(r-\sqrt{r^{2}+4 e}\right) t\right]-a(1+\varphi)(r-a) G e^{-(a-r) t} /[a(r-a)+e]
$$

from where we observe that $z^{S}=c^{S}-v^{S}=0$, i.e., $c^{S}=v^{S}$. Since $c^{S}+v^{S}=\theta$, we have $c^{S}=v^{S}=\theta / 2$. From (A7.4) and (A7.3), we have:

$$
\begin{aligned}
& c-v=C_{3} e^{\frac{1}{2}\left(r-\sqrt{r^{2}+4 e}\right) t}-a(1+\varphi)(r-a) G e^{-(a-r) t} /[a(r-a)+e] \\
& c+v=\theta-(1-\varphi) G e^{(r-a) t}
\end{aligned}
$$

Note that, because $\beta=1$, we have:

$$
\dot{W}=c-v=C_{3} e^{\frac{1}{2}\left(r-\sqrt{r^{2}+4 e}\right) t}-a(1+\varphi)(r-a) G e^{-(a-r) t} /[a(r-a)+e]
$$

and the optimal controls are:

$$
\begin{aligned}
& 2 c=\theta+C_{3} e^{\frac{1}{2}\left(r-\sqrt{r^{2}+4 e}\right) t}-\{(1-\varphi)+a(1+\varphi)(r-a) /[a(r-a)+e]\} G e^{(r-a) t} \\
& 2 v=\theta-C_{3} e^{\frac{1}{2}\left(r-\sqrt{r^{2}+4 e}\right) t}+\{a(1+\varphi)(r-a) /[a(r-a)+e]-(1-\varphi)\} G e^{(r-a) t}
\end{aligned}
$$

The constants of integration are determined by the system:

$$
\begin{aligned}
& z(0)=\theta-(1+\varphi) G+(1+\beta) \mu(0)=C_{3}-a(1+\varphi)(r-a) G /[a(r-a)+e] \\
& \dot{z}(0)=-(1+\varphi)(r-a) G+2(r \mu(0)+e W(0))=\frac{1}{2}\left(r-\sqrt{r^{2}+4 e}\right) C_{3}-a(1+\varphi)(r-a)^{2} G /[a(r-a)+e]
\end{aligned}
$$

and $\ddot{c}(0)-\ddot{v}(0)=-(1+\varphi)(r-a)^{2} G+2 r(r \mu(0)+e W(0))+2 e z(0)$, from where wrt (A7.4), we get the third equation:

$$
-(1+\varphi)(r-a)^{2} G+2 r(r \mu(0)+e W(0))+2 e\left[C_{3}-\frac{a(1+\varphi)(r-a)}{a(r-a)+e} G\right]=\frac{1}{4}\left(r-\sqrt{r^{2}+4 e}\right)^{2} C_{3}-\frac{a(1+\varphi)(r-a)^{3}}{a(r-a)+e} G
$$

We have three equations in three unknowns $\mu(0), G$ and $C_{3}$.

A8. The Legendre-Clebsch condition of concavity of the Hamiltonian wrt the control variables is satisfied, as $\left[\begin{array}{ll}H_{c c} & H_{c v} \\ H_{v c} & H_{v V}\end{array}\right]=\left[\begin{array}{cc}-1 & 0 \\ 0 & -1\end{array}\right]$ is negative definite. This guarantees a maximum of the Hamiltonian. Plugging the respective expressions of $C$ and $V$ from (18) and (19) in (15) gives the maximized Hamiltonian:

$$
H^{0}=(\theta-\lambda)^{2} / 2+(\lambda \varphi-\mu)^{2} / 2+(\lambda+\alpha \mu) a K-e W^{2} / 2
$$

from which the Hessian matrix: $\left[\begin{array}{ll}H_{K K} & H_{K W} \\ H_{W K} & H_{W W}\end{array}\right]=\left[\begin{array}{cc}0 & 0 \\ 0 & -e\end{array}\right]$ is negative semi-definite. This ensures that the necessary conditions are also sufficient for optimality.

A9. The proof is identical to that for Lemma 2.

A10. Equating the RHS of (20)-(21)-(16)-(17) to 0 and solving by identification and substitution, we get:

$$
\begin{aligned}
& \lambda^{S}=\alpha^{2} \theta a /\left\{(1+\varphi \alpha)[(1+\alpha \varphi) a-r]+\alpha^{2} a\right\} \\
& \mu^{S}=-\alpha \theta(a-r) /\left\{(1+\varphi \alpha)[(1+\alpha \varphi) a-r]+\alpha^{2} a\right\}
\end{aligned}
$$

and $K^{S}$ and $W^{S}$ as given in (11). Note that $r<a$ implies that $r<(1+\varphi \alpha) a$, which ensures a feasible steady 
state. Plugging the expressions in (18) and (19), respectively, and simplifying, yields $c^{S}$ and $v^{S}$ in (22). From (22), it can be shown that the limiting transversality conditions are satisfied for the saddle-paths because:

$$
\begin{aligned}
& \lim _{t \mapsto+\infty} e^{-r t} \lambda(t) K(t)=\lim _{t \mapsto+\infty}\left[\alpha^{2} \theta^{2} a[(1+\varphi \alpha) a-r] e^{-r t} / a\left\{(1+\varphi \alpha)[(1+\alpha \varphi) a-r]+\alpha^{2} a\right\}^{2}\right]=0 \\
& \lim _{t \mapsto+\infty} e^{-r t} \mu(t) W(t)=\lim _{t \mapsto+\infty}\left[-r \alpha^{2} \theta^{2}(a-r)^{2} e^{-r t} / e\left\{(1+\varphi \alpha)[(1+\alpha \varphi) a-r]+\alpha^{2} a\right\}^{2}\right]=0
\end{aligned}
$$

This ensures the uniqueness of the globally optimal solution.

A11. To analyze the stability of the steady state, we compute the Jacobian matrix of the canonical system (20)-(21)(16)-(17), that is:

$$
J=\left[\begin{array}{cccc}
a & 0 & 1+\varphi^{2} & -\varphi \\
\alpha a & 0 & -\varphi & 1 \\
0 & 0 & r-a & -\alpha a \\
0 & e & 0 & r
\end{array}\right]
$$

Given that $\lambda$ and $\mu$ are evaluated at their steady-state value, we compute the determinant:

$$
|J|=a e\left\{(1+\varphi \alpha)[(1+\alpha \varphi) a-r]+\alpha^{2} a\right\}
$$

which is positive for $r<a$, and the sum of the principal minors of $J$ of order 2 minus the squared discounting rate:

$$
\Psi=-a(a-r)-e=-a(a-r)-e
$$

which is negative. Both signs imply that a saddle-point exists.

A12. To determine whether the optimal path is monotonic or cyclical, we compute the expression (Dockner, 1985):

$$
\Omega=\Psi^{2}-4|J|=[a(a-r)+e]^{2}-4 a e\left\{(1+\varphi \alpha)[(1+\alpha \varphi) a-r]+\alpha^{2} a\right\}
$$

A positive (negative) sign of $\Omega$ indicates that convergence to the saddle-point is monotonic (spiraling) near the steady state. Because the sign of $\Omega$ is ambiguous, a limit value analysis highlights the role of $a, e, \varphi$, and $\alpha$ in the sign of $\Omega$ for a given $r<a$ (see Table A12.1). The results suggest that $\Omega$ can be either positive or negative depending on the parameters value. For any given $a$, and $e$, convergence to the saddle-point is monotonic near the steady state. However, we get $\lim _{\alpha \mapsto 0^{+}} \Omega>0$ and $\lim _{\alpha \rightarrow \infty} \Omega=-\infty$, as well as $\partial \Omega / \partial \alpha<0$, which implies that there is a threshold $\tilde{\alpha}>0$ such that for any $\alpha>\tilde{\alpha}(\alpha<\tilde{\alpha})$, we have $\Omega<0(\Omega>0)$.

\begin{tabular}{|c|l|}
\hline $\lim _{a \mapsto 0^{+}} \Omega=e^{2}$ & $\lim _{a \mapsto \infty} \Omega=\infty$ \\
\hline $\lim _{e \mapsto 0^{+}} \Omega=a^{2}(a-r)^{2}$ & $\lim _{e \mapsto \infty} \Omega=\infty$ \\
\hline $\lim _{\varphi \mapsto 0^{+}} \Omega=a^{2}\left[(a-r)^{2}-2 e\left(1+2 \alpha^{2}\right)\right]+e(2 r a+e)$ & $\lim _{\varphi \mapsto \infty} \Omega=-\infty$ \\
\hline $\lim _{\alpha \mapsto 0^{+}} \Omega=[a(a-r)-e]^{2}$ & $\lim _{\alpha \mapsto \infty} \Omega=-\infty$ \\
\hline
\end{tabular}

Table A12.1. Limit value analysis

A similar result is obtained for $\varphi$, that is, for a high value of $\tilde{\varphi}>0$ such that for any $\varphi>\tilde{\varphi}$, we get $\Omega<0$.

A13. Comparing the results from (11) and (22) for $\varphi=0$ and $\alpha=\beta>0$ proves (23)-(26).

A14. To compute the numerical solution of the consumption and production-based waste generation optimal control problems, we solve the related Hamilton-Jacobi-Bellman (HJB) equations. The HJB equation is:

$$
r V^{1}=c(\theta-c / 2)-e W^{2} / 2-v^{2} / 2+V_{K}^{1}(a K-c+\varphi v)+V_{W}^{1}(\beta c-v)
$$

for consumption-based waste generation, and:

$$
r V^{2}=c(\theta-c / 2)-e W^{2} / 2-v^{2} / 2+V_{K}^{2}(a K-c+\varphi v)+V_{W}^{2}(\alpha a K-v)
$$


for production-based waste generation, where $V^{i}(K, W), i=1,2$, are the value functions respectively associated with the consumption and production-based waste generation optimal control problems. Assuming interior solutions, the necessary conditions are:

$$
c=\theta-V_{K}^{1}+\beta V_{W}^{1}, \quad v=\varphi V_{K}^{1}-V_{W}^{1}
$$

for consumption-based waste generation, and:

$$
c=\theta-V_{K}^{2}, \quad v=\varphi V_{K}^{2}-V_{W}^{2}
$$

for production-based waste generation. Using the necessary conditions in their corresponding HJB equations, we get:

$$
r V^{1}=\left(\theta+\beta V_{W}^{1}-V_{K}^{1}\right)^{2} / 2-\left(\varphi V_{K}^{1}-V_{W}^{1}\right)^{2} / 2-e W^{2} / 2+a V_{K}^{1} K
$$

for consumption-based waste generation, and:

$$
r V^{2}=\left(\theta-V_{K}^{2}\right)^{2} / 2-\left(\varphi V_{K}^{2}-V_{W}^{2}\right)^{2} / 2-e W^{2} / 2+a\left(V_{K}^{2}+\alpha V_{W}^{2}\right) K
$$

for production-based waste generation. For the value functions, we consider the following conjectures, that is:

$$
V^{1}=\psi_{1}+\psi_{2} K+\psi_{3} W+\psi_{4} K^{2}+\psi_{5} W^{2}+\psi_{6} K W
$$

for consumption-based waste generation, where $\psi_{1}, . ., \psi_{6}$ are real parameters, and:

$$
V^{2}=\xi_{1}+\xi_{2} K+\xi_{3} W+\xi_{4} K^{2}+\xi_{5} W^{2}+\xi_{6} K W
$$

for production-based waste generation, where $\xi_{1}, . ., \xi_{6}$ are real parameters.

Depending on whether the waste generation results from production or consumption, one solves a system of 6 algebraic equations in 6 unknowns in each case, that is:

$$
\begin{aligned}
& r \psi_{1}-\left(\theta+\psi_{2}\right)^{2} / 2-\left(\varphi \psi_{2}+\psi_{3}\right)^{2} / 2=0 \\
& r \psi_{3}-\left(1+\varphi^{2}\right) \psi_{2} \psi_{6}+\left(\theta+\varphi \psi_{3}\right) \psi_{6}-2\left(\psi_{3}-\varphi \psi_{2}\right) \psi_{5}=0 \\
& {\left[r-a-2\left(1+\varphi^{2}\right) \psi_{4}+\varphi \psi_{6}\right] \psi_{2}-\left(\alpha a+\psi_{6}\right) \psi_{3}+2\left(\theta+\varphi \psi_{3}\right) \psi_{4}=0} \\
& -2\left(\alpha a-2 \varphi \psi_{4}\right) \psi_{5}+\left[r-a-2\left(1+\varphi^{2}\right) \psi_{4}-2 \psi_{5}+\varphi \psi_{6}\right] \psi_{6}=0 \\
& {\left[r-2\left(1+a+\varphi^{2} \psi_{4}\right)\right] \psi_{4}-\left(\alpha a-2 \varphi \psi_{4}+\psi_{6} / 2\right) \psi_{6}=0} \\
& {\left[r-2\left(\psi_{5}-\varphi \psi_{6}\right)\right] \psi_{5}-\left(1+\varphi^{2}\right) \psi_{6}{ }^{2} / 2+e / 2=0}
\end{aligned}
$$

for consumption-based waste generation, and:

$$
\begin{aligned}
& r \psi_{1}-\left(\theta-\psi_{2}\right)^{2} / 2-\left(\varphi \psi_{2}-\psi_{3}\right)^{2} / 2-\beta\left(\theta-\psi_{2}+\beta \psi_{3} / 2\right) \psi_{3}=0 \\
& r \psi_{3}-2\left[\beta \theta-(\beta+\varphi) \psi_{2}+\left(1+\beta^{2}\right) \psi_{3}\right] \psi_{5}+\left[\theta-\left(1+\varphi^{2}\right) \psi_{2}+(\beta+\varphi) \psi_{3}\right] \psi_{6}=0 \\
& (r-a) \psi_{2}+2\left[\theta-\left(1+\varphi^{2}\right) \psi_{2}+(\beta+\varphi) \psi_{3}\right] \psi_{4}-\left[\beta \theta+(\beta+\varphi) \psi_{2}+\left(1+\beta^{2}\right) \psi_{3}\right] \psi_{6}=0 \\
& (r-a) \psi_{6}+2\left[2(\beta+\varphi) \psi_{5}-\left(1+\varphi^{2}\right) \psi_{6}\right] \psi_{4}-\left[2\left(1+\beta^{2}\right) \psi_{5}-(\beta+\varphi) \psi_{6}\right] \psi_{6}=0 \\
& r \psi_{4}-2\left[a+\left(1+\varphi^{2}\right) \psi_{4}-(\beta+\varphi) \psi_{6}\right] \psi_{4}-\left(1+\beta^{2}\right) \psi_{6}^{2} / 2=0 \\
& {\left[r-2\left(1+\beta^{2}\right) \psi_{5}\right] \psi_{5}+\left[2(\beta+\varphi) \psi_{5}-\left(1+\varphi^{2}\right) \psi_{6} / 2\right] \psi_{6}+e / 2=0}
\end{aligned}
$$


for production-based waste generation. In general, each system of algebraic equations above may admit zero, one or multiple solutions. The selection of an admissible solution for each system, if any, is based on the global asymptotic stability criterion. In this regard, the necessary conditions related to consumption-based waste generation rewrite:

$$
\begin{aligned}
& c=\theta-\psi_{2}+\beta \psi_{3}-\left(2 \psi_{4}-\beta \psi_{6}\right) K-\left(\psi_{6}-2 \beta \psi_{5}\right) W \\
& v=\varphi \psi_{2}-\psi_{3}+\left(2 \varphi \psi_{4}-\psi_{6}\right) K+\left(\varphi \psi_{6}-2 \psi_{5}\right) W
\end{aligned}
$$

and the necessary conditions related to production-based waste generation become:

$$
\begin{aligned}
& c=\theta-\xi_{2}-2 \xi_{4} K-\xi_{6} W \\
& v=\varphi \xi_{2}-\xi_{3}+\left(2 \varphi \xi_{4}-\xi_{6}\right) K+\left(\varphi \xi_{6}-2 \xi_{5}\right) W
\end{aligned}
$$

Plugging the optimal expressions into the corresponding system of state equations, we get:

$$
\begin{aligned}
& \dot{K}=-\theta+\left(1+\varphi^{2}\right) \psi_{2}-(\beta+\varphi) \psi_{3}+\left[a+2\left(1+\varphi^{2}\right) \psi_{4}-(\beta+\varphi) \psi_{6}\right] K-\left[2(\beta+\varphi) \psi_{5}-\left(1+\varphi^{2}\right) \psi_{6}\right] W \\
& \dot{W}=\beta \theta-(\beta+\varphi) \psi_{2}+\left(1+\beta^{2}\right) \psi_{3}-\left[2(\beta+\varphi) \psi_{4}-\left(1+\beta^{2}\right) \psi_{6}\right] K+\left[2\left(1+\beta^{2}\right) \psi_{5}-(\beta+\varphi) \psi_{6}\right] W
\end{aligned}
$$

for consumption-based waste generation, and:

$$
\begin{aligned}
& \dot{K}=-\theta+\left(1+2 \varphi^{2}\right) \xi_{2}-\varphi \xi_{3}+\left[a+2\left(1+2 \varphi^{2}\right) \xi_{4}-\varphi \xi_{6}\right] K+\left[\left(1+2 \varphi^{2}\right) \xi_{6}-2 \varphi \xi_{5}\right] W \\
& \dot{W}=-\varphi \xi_{2}+\xi_{3}+\left(\alpha a-2 \varphi \xi_{4}+\xi_{6}\right) K+\left(2 \xi_{5}-\varphi \xi_{6}\right) W
\end{aligned}
$$

for production-based waste generation. Imposing a steady state for each system of state equations yields:

$$
\begin{aligned}
K^{s} & =\frac{\theta\left[2\left(2 \beta^{2}+\beta \varphi+1\right) \psi_{5}-\left(\beta \varphi^{2}+2 \beta+\varphi\right) \psi_{6}\right]-(1-\beta \varphi)^{2}\left(2 \psi_{2} \psi_{5}-\psi_{3} \psi_{6}\right)}{(1-\beta \varphi)^{2}\left(4 \psi_{4} \psi_{5}-\psi_{6}^{2}\right)+a\left[2\left(1+\beta^{2}\right) \psi_{5}-(\beta+\varphi) \psi_{6}\right]} \\
W^{s} & =\frac{a\left[\beta \theta+(\beta+\varphi) \psi_{2}\right]-a\left(1+\beta^{2}\right) \psi_{3}+\theta\left[2\left(\beta \varphi^{2}+2 \beta+\varphi\right) \psi_{4}-\left(2 \beta^{2}+\beta \varphi+1\right) \psi_{6}\right]+(1-\beta \varphi)^{2}\left(\psi_{2} \psi_{6}-2 \psi_{3} \psi_{4}\right)}{(1-\beta \varphi)^{2}\left(4 \psi_{4} \psi_{5}-\psi_{6}^{2}\right)+a\left[2\left(1+\beta^{2}\right) \psi_{5}-(\beta+\varphi) \psi_{6}\right]}
\end{aligned}
$$

for consumption-based waste generation, and:

$$
\begin{aligned}
K^{s} & =\frac{\left(1+\varphi^{2}\right)\left(2 \psi_{2} \psi_{5}-\psi_{3} \psi_{6}\right)+\theta\left(\varphi \psi_{6}-2 \psi_{5}\right)}{a\left[\left(\alpha+\varphi+2 \alpha \varphi^{2}\right) \psi_{6}-2(1+\alpha \varphi) \psi_{5}\right]-\left(1+\varphi^{2}\right)\left(4 \psi_{4} \psi_{5}-\psi_{6}^{2}\right)} \\
W^{s} & =\frac{a\left[\alpha \theta-\left(2 \alpha \varphi^{2}+\alpha+\varphi\right) \psi_{2}+(1+\alpha \varphi) \psi_{3}\right]-\theta\left(2 \varphi \psi_{4}-\psi_{6}\right)-\left(1+\varphi^{2}\right)\left(\psi_{2} \psi_{6}-2 \psi_{3} \psi_{4}\right)}{a\left[\left(\alpha+\varphi+2 \alpha \varphi^{2}\right) \psi_{6}-2(1+\alpha \varphi) \psi_{5}\right]-\left(1+\varphi^{2}\right)\left(4 \psi_{4} \psi_{5}-\psi_{6}{ }^{2}\right)}
\end{aligned}
$$

for production-based waste generation. Clearly, the positivity of the steady-state values should hold. Also, the steadystate solution given for each system of state equations, if any, should be globally asymptotically stable. The Jacobian matrix for consumption-based waste generation is:

$$
J^{1}=\left[\begin{array}{cc}
a+2\left(1+\varphi^{2}\right) \psi_{4}-(\beta+\varphi) \psi_{6} & -2(\beta+\varphi) \psi_{5}-\left(1-\varphi^{2}\right) \psi_{6} \\
-2(\beta+\varphi) \psi_{4}+\left(1+\beta^{2}\right) \psi_{6} & 2\left(1+\beta^{2}\right) \psi_{5}-(\beta+\varphi) \psi_{6}
\end{array}\right]
$$

whose trace and determinant are respectively:

$$
\begin{aligned}
\operatorname{Tr}\left(J^{1}\right)=a+2\left(1+\varphi^{2}\right) \psi_{4}+ & 2\left(1+\beta^{2}\right) \psi_{5}-2(\beta+\varphi) \psi_{6} \\
\left|J^{1}\right|=\left[a+2\left(1+\varphi^{2}\right) \psi_{4}-(\varphi+\beta) \psi_{6}\right]\left[2\left(1+\beta^{2}\right) \psi_{5}-(\beta+\varphi) \psi_{6}\right] & -\left[2(\beta+\varphi) \psi_{5}+\left(1-\varphi^{2}\right) \psi_{6}\right]\left[2(\beta+\varphi) \psi_{4}-\left(1+\beta^{2}\right) \psi_{6}\right]
\end{aligned}
$$

On the other hand, the Jacobian matrix for consumption-based waste generation is: 


$$
J=\left[\begin{array}{cc}
a+2\left(1+2 \varphi^{2}\right) \xi_{4}-\varphi \xi_{6} & \left(1+2 \varphi^{2}\right) \xi_{6}-2 \varphi \xi_{5} \\
\alpha a-2 \varphi \xi_{4}+\xi_{6} & 2 \xi_{5}-\varphi \xi_{6}
\end{array}\right]
$$

whose trace and determinant are respectively:

$$
\begin{aligned}
& \operatorname{Tr}\left(J^{2}\right)=a+2\left(1+2 \varphi^{2}\right) \xi_{4}+2 \xi_{5}-2 \varphi \xi_{6} \\
& \left|J^{2}\right|=\left[a+2\left(1+2 \varphi^{2}\right) \xi_{4}-\varphi \xi_{6}\right]\left(2 \xi_{5}-\varphi \xi_{6}\right)-\left[\left(1+2 \varphi^{2}\right) \xi_{6}-2 \varphi \xi_{5}\right]\left(\alpha a-2 \varphi \xi_{4}+\xi_{6}\right)
\end{aligned}
$$

Based on the global asymptotic stability conditions, that is, $\operatorname{Tr}\left(J^{i}\right)<0$ and $\left|J^{i}\right|>0, i=1,2$, the solution of $\psi_{1}, . ., \psi_{6}$ for consumption-based waste generation, and $\theta_{1}, . ., \theta_{6}$ for production-based waste generation can be selected.

\section{References}

Andreoni, J., Levinson, A., 2001. The simple analytics of the Environmental Kuznets Curve. Journal of Public Economics, 80(2), 269-286.

Azomahou, T., Boucekkine, R., Nguyen Van, P., 2012. Vintage capital and the diffusion of clean technologies. International Journal of Economic Theory, 8(3), 277-300.

Barnes, D.K.A., 2002. Invasions by marine life on plastic debris. Nature, 416, 808-809.

Bassetti, T., Benos, N., Karagiannis, S., 2013. $\mathrm{CO}_{2}$ emissions and income dynamics: What does the global evidence tell us?. Environmental and Resource Economics, 54(1), 101-125.

Bernard, J.-T., Gavin, M., Khalaf, L., Voia, M., 2015. Environmental Kuznets Curve: Tipping points, uncertainty and weak identification. Environmental and Resource Economics, 60(2), 285315.

Boucekkine, R., El Ouardighi, 2016. Optimal growth with pollution waste and recycling. In: Feichtinger, G. (Ed.). Dynamic Perspectives on Managerial Decision Making. Springer.

Boucekkine, R., Pommeret, A., Prieur, F., 2013. Technological vs. ecological switch and the Environmental Kuznets Curve. American Journal of Agricultural Economics, 95(2), 252-260.

Boucekkine, R., de la Croix, D., Licandro, O., 2011. Vintage capital theory: Three breakthroughs. In: de La Grandville, O. (Ed.). Economic Growth and Development. Emerald.

Christiano, L., 1990. Linear-quadratic approximation and value-function iteration: A comparison. Journal of Business and Economic Statistics, 8(1), 99-113.

Coderoni, S., Esposti, R., 2014. Is there a long-term relationship between agricultural GHG emissions and productivity growth? A dynamic panel data approach. Environmental and Resource Economics, 58(2), 273-302.

de Bruyn, S., Opschoor, J., 1997. Developments in the throughput-income relationship: Theoretical and empirical observations. Ecological Economics, 20(3), 255-268.

Dinda, S., 2004. Environmental Kuznets curve hypothesis: A survey. Ecological Economics, 49(4), 431-455.

Dinda, S., 2005. A theoretical basis for the Environmental Kuznets Curve. Ecological Economics, 53(3), 403-413.

Dockner, E., 1985. Local stability in optimal control problems with two state variables. In: Feichtinger, G. (Ed.). Optimal Control Theory and Economic Analysis (vol. 2). North Holland.

Dockner, E., Feichtinger, G., 1991. On the optimality of limit cycles in dynamic economic systems. Journal of Economics, 53(1), 31-50.

El Ouardighi, F., Benchekroun, H., Grass, D., 2014. Controlling pollution and environmental absorption capacity. Annals of Operations Research, 220(1), 111-133. 
El Ouardighi, F., Benchekroun, H., Grass, D., 2016. Self-regenerating environmental absorption efficiency and the Soylent Green scenario. Annals of Operations Research, 238(1), 179-198.

Eriksen, M., Maximenko, N., Thiel, M., Cummins, A., Lattin, G., Wilson, S., Hafner, J., Zellers, A., Rifman, S., 2013. Plastic pollution in the South Pacific subtropical gyre. Marine Pollution Bulletin, 68(1-2), 71-76.

Fodha, M., Magris, F., 2015. Recycling waste and endogenous fluctuations in an OLG model. International Journal of Economic Theory, 11(4), 405-427.

Grass, D., Caulkins, J.P., Feichtinger, G., Tragler, G., Behrens, D.A., 2008. Optimal Control of Nonlinear Processes with Applications in Drugs, Corruption, and Terror. Springer.

Grossman, G., Krueger, A., 1995. Economic growth and the environment. Quarterly Journal of Economics, 110(2), 353-377.

John, A., Pecchenino, R., 1994. An overlapping generations model of growth and the environment. Economic Journal, 104(427), 1393-1410.

Kydland, F., Prescott, E., 1982. Time to build and aggregate fluctuations. Econometrica, 50(6), 1345-1370.

Kijima, M., Nishide, K., Ohyama,A., 2010. Economic models for the environmental Kuznets curve: A survey. Journal of Economic Dynamics and Control, 34(4), 1187-1203.

Law, K., Moret-Ferguson, S., Maximenko, N., Proskurowski, G., Peacock, E., Hafner, J., Reddy, C.M., 2010. Plastic accumulation in the North Atlantic subtropical gyre. Science, 329(5996), 1185-1188.

List, J.A., Gallet, C.A., 1999. The Environmental Kuznets Curve: does one size fit all? Ecological Economics, 31(3), 409-423.

Lusky, R., 1976. A model of recycling and pollution control. Canadian Journal of Economics, 9(4), 91-101.

Martin, R.E., 1982. Monopoly power and the recycling of raw materials. The Journal of Industrial Economics, 30(4), 104-419.

PlasticsEurope, 2015. Plastics - The Facts 2014/2015. An Analysis of European Plastics Production, Demand and Waste Data. Belgium.

Prieur, F., 2009. The environmental Kuznets curve in a world of irreversibility. Economic Theory, 40(1), 57-90.

Rebelo, S., 1991. Long-run policy analysis and long-run growth. Journal of Political Economy, 99(3), 500-521.

Roca, J., 2003. Do individual preferences explain Environmental Kuznets Curve? Ecological Economics, 45(1), 3-10.

Seierstad, A., Sydsæter, K., 1987. Optimal Control Theory with Economic Applications. North Holland.

Sengupta, R.P., 1997. CO2 emission-income relationship: policy approach for climate control. Pacific Asia Journal of Energy, 7(2), 207-229

Sephton, P., Mann, J., 2016. Compelling evidence of an Environmental Kuznets Curve in the United Kingdom. Environmental and Resource Economics, 64(2), 301-315.

Stern, D.I., 2004. The rise and fall of the Environmental Kuznets Curve. World Development, 32(8), 1419-1439.

Stokey, N., 1998. Are there limits to growth? International Economic Review, 39(1), 1-31.

Tucker, M., 1995. Carbon dioxide emissions and global GDP. Ecological Economics, 15(3), 215223. 


\begin{tabular}{|c|c|c|c|c|}
\hline $\begin{array}{l}\text { ESSEC Business School } \\
3 \text { avenue Bernard-Hirsch } \\
\text { CS } 50105 \text { Cergy } \\
95021 \text { Cergy-Pontoise Cedex } \\
\text { France } \\
\text { Tel. }+33 \text { (0) } 134433000 \\
\text { www.essec.edu }\end{array}$ & $\begin{array}{l}\text { ESSEC Executive Education } \\
\text { CNIT BP } 230 \\
92053 \text { Paris-La Défense } \\
\text { France } \\
\text { Tel. + } 33 \text { (0) } 146924900 \\
\text { www.executive-education.essec.edu }\end{array}$ & $\begin{array}{l}\text { ESSEC Asia-Pacific } \\
5 \text { Nepal Park } \\
\text { Singapore } 139408 \\
\text { Tel. +65 } 68849780 \\
\text { www.essec.edu/asia }\end{array}$ & $\begin{array}{l}\text { ESSEC Africa-Atlantic } \\
\text { Plage des Nations } \\
\text { Sidi Bouknadel } \\
\text { Rabat-Salé } \\
\text { Morocco } \\
\text { Tel. +212 } \\
\text { (0)5 } 30104019 \\
\text { www.essec.edu }\end{array}$ & $\begin{array}{l}\text { ESSEC Africa-Indian Ocean } \\
\text { Royal Road, Pierrefonds } \\
\text { Mauritius } \\
\text { Tel. +230 } 4012400 \\
\text { www.essec.edu } \\
\text { www.icsia.mu }\end{array}$ \\
\hline
\end{tabular}

\section{- MOROCCO}

\section{Contacts}

Centre de Recherche

+33 (0)134433091

research.center@essec.fr

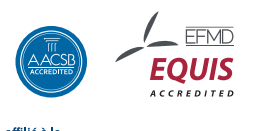

Cí CCI PARIS ILE-DE-FRANCE

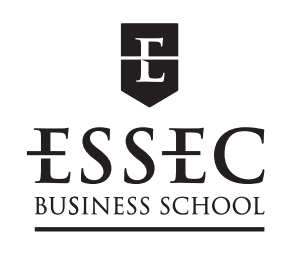




\begin{tabular}{|c|c|c|c|c|}
\hline $\begin{array}{l}\text { ESSEC Business School } \\
3 \text { avenue Bernard-Hirsch } \\
\text { CS } 50105 \text { Cergy } \\
95021 \text { Cergy-Pontoise Cedex } \\
\text { France } \\
\text { Tel. }+33 \text { (0) } 134433000 \\
\text { www.essec.edu }\end{array}$ & $\begin{array}{l}\text { ESSEC Executive Education } \\
\text { CNIT BP } 230 \\
92053 \text { Paris-La Défense } \\
\text { France } \\
\text { Tel. + } 33 \text { (0) } 146924900 \\
\text { www.executive-education.essec.edu }\end{array}$ & $\begin{array}{l}\text { ESSEC Asia-Pacific } \\
5 \text { Nepal Park } \\
\text { Singapore } 139408 \\
\text { Tel. +65 } 68849780 \\
\text { www.essec.edu/asia }\end{array}$ & $\begin{array}{l}\text { ESSEC Africa-Atlantic } \\
\text { Plage des Nations } \\
\text { Sidi Bouknadel } \\
\text { Rabat-Salé } \\
\text { Morocco } \\
\text { Tel. +212 } \\
\text { (0)5 } 30104019 \\
\text { www.essec.edu }\end{array}$ & $\begin{array}{l}\text { ESSEC Africa-Indian Ocean } \\
\text { Royal Road, Pierrefonds } \\
\text { Mauritius } \\
\text { Tel. +230 } 4012400 \\
\text { www.essec.edu } \\
\text { www.icsia.mu }\end{array}$ \\
\hline
\end{tabular}

\section{- MOROCCO}

\section{Contacts}

Centre de Recherche

+33 (0)134433091

research.center@essec.fr

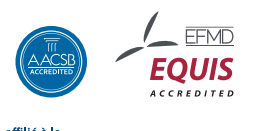

Cí CCI PARIS ILE-DE-FRANCE

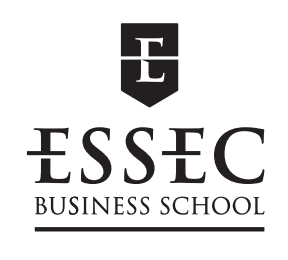

